\title{
MODELAGEM BIM PARA O REGISTRO DIGITAL DO PATRIMÔNIO ARQUITETÔNICO MODERNO
}

MODELO BIM PARA EL REGISTRO DIGITAL DEL PATRIMONIO ARQUITECTÓNICO MODERNO

BIM MODELING FOR DIGITAL REGISTRATION OF MODERN ARCHITECTURAL HERITAGE

COSTA, HELIARA APARECIDA

Mestre em Engenharia de Edificações e Ambiental, doutoranda em Arquitetura e Urbanismo pela Universidade de São Paulo - IAU, heliara@usp.br

\section{SOUZA, MARCIO PRESENTE DE}

Mestre em Arquitetura e Urbanismo, doutorando em Arquitetura e Urbanismo pela Universidade de São Paulo - IAU, marciopresente@usp.br

\section{BALDESSIN, GUILHERME QUINILATO}

Graduando em Arquitetura e Urbanismo pela Universidade de São Paulo - IAU, quilherme.baldessin@usp.br

\section{ALBANO, GABRIELA}

Graduanda em Arquitetura e Urbanismo pela Universidade de São Paulo - IAU, gabriela.albano@usp.br

\section{FABRICIO, MÁRCIO MINTO}

Professor Associado do Departamento de Arquitetura e Urbanismo da Universidade de São Paulo - IAU, marcio.m.fabricio@usp.br

\section{RESUMO}

A metodologia Building Information Modelling (BIM) é, atualmente, uma das principais expressões das inovações tecnológicas digitais aplicadas à Arquitetura, Engenharia, Construção e Operação. Trata-se de um instrumento capaz de analisar grande quantidade de informações, por meio de um modelo virtual que gerencia o ciclo de vida de um edifício, voltado as fases anteriores a construção. Para edifícios construídos tem-se o conceito de HBIM (Historic Building Information Modelling) como alternativa de gerenciamento, na qual objetos paramétricos são construídos a partir de dados de edifícios históricos. No entanto, componentes destinados ao registro histórico são raros em bibliotecas BIM e exigem grande esforço de modelagem, necessitando de protocolos e especificações relativos aos seus processos. Este artigo objetiva identificar e analisar meios para a modelagem de componentes de um edifício histórico em BIM, partindo de um elemento do edifício moderno E1, localizado no campus USP São Carlos - SP. O método consistiu em revisão bibliográfica, levantamentos no local, modelagem paramétrica e avaliação das formas de desenvolvimento dos componentes, com uso de software BIM. Os resultados identificam três processos distintos de modelagem: Família de Sistema, Família Composta e Família Modelada no Local. A contribuição é a descrição e a discussão dos procedimentos adotados, as potencialidades e limitações de cada processo e sua aplicação para estudos similares. Os elementos produzidos foram disponibilizados em um repositório público, a fim de possibilitar o registro, documentação e o uso em projetos de gestão, manutenção, preservação e reconstrução do patrimônio estudado, e também como um modelo exemplificado para bibliotecas HBIM a serem futuramente construídas.

PALAVRAS-CHAVE: HBIM; famílias revit; patrimônio histórico.

\section{RESUMEN}

La metodología BIM (Building Information Modelling) es la expresión actual de las innovaciones tecnológicas digitales aplicadas a Arquitectura, Ingeniería, Construcción y Operación, como un instrumento capaz de analizar grandes cantidades de información, a través de un modelo virtual que gestiona el ciclo de vida de un edificio enfrentando las fases previas a la construcción. Para los edificios construidos, tenemos el concepto de HBIM (Historic Building Information Modelling) como una alternativa de gestión, en la que los objetos paramétricos se construyen a partir de datos de edificios históricos. Sin embargo, los componentes destinados al registro histórico son raros en las bibliotecas BIM y requieren un gran esfuerzo de modelado, ya que requieren protocolos y especificaciones relacionadas con sus procesos. Este artículo tiene como objetivo identificar y analizar medios para el modelado de componentes de un edificio histórico en BIM, a partir de un elemento del moderno edificio E1, ubicado en el campus USP São Carlos - SP. El método consistió en una revisión bibliográfica, encuestas in situ, modelado paramétrico y evaluación de las formas de desarrollo de componentes, utilizando el software BIM. Los resultados identifican tres procesos de modelado distintos: Familia del Sistema, Familia Compuesta y Familia Modelada en el Local. La contribución es la descripción y discusión de los procedimientos adoptados, el potencial y las limitaciones de cada proceso y su aplicación para estudios similares. Los elementos producidos se pusieron a disposición en un repositorio público, a fin de permitir el registro, la documentación y el uso en proyectos de gestión, mantenimiento, preservación y reconstrucción del patrimonio estudiado y también como un modelo de ejemplo para las bibliotecas HBIM que se construirán en el futuro.

PALABRAS CLAVES: HBIM; familias revit; patrimonio histórico. 


\section{ABSTRACT}

The BIM (Building Information Modelling) methodology is the current expression of digital technological innovations applied to Architecture, Engineering, Construction and Operation, as an instrument capable of analyzing large amounts of information, through a virtual model that manages the life cycle of a building, facing the phases prior to construction. For constructed buildings, we have the concept of HBIM (Historic Building Information Modelling) as a management alternative, in which parametric objects are constructed from historical building data. However, components intended for historical registration are rare in BIM libraries and require a great deal of modeling effort, requiring protocols and specifications related to their processes. This article aims to identify and analyze means for the modeling of components of a historic building in BIM, starting from an element of the modern building E1, located on the USP São Carlos campus - SP. The method consisted of bibliographic review, on-site surveys, parametric modeling and evaluation of the forms of component development, using BIM software. The results identify three distinct modeling processes: System Family, Composite Family and Modeled Local Family. The contribution is the description and discussion of the procedures adopted, the potential and limitations of each process and its application for similar studies. The elements produced were made available in a public repository, in order to enable the registration, documentation and use in projects of management, maintenance, preservation and reconstruction of the studied heritage and also as an example model for HBIM libraries to be built in the future.

KEYWORDS: HBIM; revit families; historical heritage.

\section{INTRODUCCÃO}

De acordo com a Unesco (1972) o patrimônio cultural inclui, entre outros, as obras arquitetônicas - em grupos de construções isoladas ou reunidas, podendo considerar ou não a integração à paisagem - cujo valor seja considerado universal e excepcional do ponto de vista histórico, artístico ou científico. É de vital importância, documentar de forma precisa esses bens, tanto para a compreensão do seu valor (material e imaterial), quanto para dar suporte à sua manutenção e preservação.

Para Lu e Pan (2010), o desenvolvimento das novas tecnologias - como redes de computadores, multimídia, realidade virtual e inteligência artificial - são bases para novos métodos de conservação, pesquisa, exibição interativa e utilização do patrimônio. Dezen-Kempter et al. (2015) reforçam que essas novas tecnologias digitais são instrumentos para produzir um inventário do patrimônio edificado, podendo auxiliar na sua manutenção e preservação.

Em se tratando de edificações históricas, estas exigem atenção especial nas adaptações necessárias diante das novas funções assumidas ao longo do seu ciclo de vida, por conta de reformas e alterações necessárias para os novos usos, tanto quanto para sua manutenção e conservação de suas características e valores. Deste modo, a documentação as-built e as-is são meios importantes de consulta e de controle. Com as novas tecnologias, essa documentação vem sendo realizada como modelos digitais 3D de construção e informação integrados, permitindo simulações e antecipação dos resultados no apoio à tomada de decisão.

O conceito BIM (Building Information Modelling) é considerado a expressão atual dessas inovações no setor de arquitetura e construção (SUCCAR; KASSEM, 2015). Eastman et al. (2014, p. 13) definem o BIM como "uma tecnologia de modelagem e um conjunto associado de processos para produzir, comunicar e analisar modelos de construção". É composto por uma plataforma digital que integra políticas, processos e tecnologias para o gerenciamento da informação durante todo o ciclo de vida de um edifício (SUCCAR, 2009), utilizando um modelo tridimensional do edifício construído digitalmente com dados paramétricos, tendo como princípio a interoperabilidade, o que permite que um mesmo arquivo de projeto, com diferentes extensões, possa ser submetido a diferentes análises, pois possui um formato suportado por diferentes programas computacionais, facilitando trocas de dados e interação entre os especialistas envolvidos (BRÍGITTE; RUSCHEL, 2016).

Nessa perspectiva, o BIM possui grande potencial para uso em edifícios históricos, ganhando caráter de apoio tanto para o registro e documentação, quanto para o gerenciamento de sua conservação. Entre os principais benefícios do uso do BIM em projetos de conservação do patrimônio histórico, tem-se a capacidade de integrar e combinar informações consolidadas e dados geométricos e semânticos em um único modelo virtual 3D, criando uma base de conhecimento sobre o ativo patrimonial, o que permite extração de dados e documentação do projeto; capacidade de geração de múltiplas propostas de intervenção; facilidade de organização, análise, manipulação das informações coletadas, ao mesmo tempo em que evidencia incoerências entre o projeto e o edifício construído em sua fase de operação (uso e manutenção) e de possíveis reformas, restaurações, requalificações e demolições; compartilhar informações entre uma equipe multidisciplinar com maior eficiência, além da capacidade interoperável; simular o desempenho e a prevenção dos riscos, como o estrutural e de propriedade dos materiais; visualização antecipada e mais precisa, entre outras. Desta forma, um modelo histórico de informações em BIM pode ser uma ferramenta confiável para a tomada de decisão no gerenciamento do ciclo de vida do patrimônio, alcançando cada vez mais relevância nesse processo a longo prazo (GROETELAARS, 2015; CUPERSCHMID; FABRICIO; FRANCO JR, 2019; DORE; MURPHY, 2017; HISTORIC ENGLAND, 2018).

Esse potencial fez surgir o HBIM, uma extensão do BIM para aplicações em edifícios de valor histórico. O conceito HBIM foi introduzido por Murphy, McGovern e Pavia (2007), sendo aprimorado ao longo do tempo. 
Inicialmente, foi definido como um processo de projeto em que, por meio de uma engenharia reversa e tecnologia de varredura a laser, obtém-se um protótipo virtual completo da edificação. Esse processo partia da (a) criação de uma biblioteca de objetos paramétricos, com base em estudo de teorias e regras de elementos arquitetônicos históricos em 3D, com uso de script GDL e operações booleanas em um software BIM; para em seguida realizar um (b) mapeamento e a correlação dos elementos dessa biblioteca em uma nuvem de pontos do edifício em estudo, a fim de realizar ajustes desses elementos diretamente no modelo, gerando por fim um sistema completo do patrimônio no software (MURPHY; MCGOVERN; PAVIA, 2007). Posteriormente, em 2009, ao processo é acrescentado a captura de imagens digitais e seu respectivo processamento fotogramétrico, auxiliando na determinação da geometria, textura e cores (MURPHY; MCGOVERN; PAVIA, 2009). Em 2013, os autores definiram o HBIM como uma solução "na qual objetos paramétricos interativos que representam elementos arquitetônicos são construídos a partir de dados históricos, cujos elementos (incluindo detalhes por trás da superfície de varredura) são mapeados com precisão em uma nuvem de pontos ou em pesquisa baseada em imagem" (MURPHY; MCGOVERN; PAVIA, 2013, p. 89). De acordo com os mesmos, esses "detalhes por trás da varredura" são as informações sobre os métodos de construção, composição de materiais, estilos arquitetônicos, enfatizando que a principal vantagem do HBIM é a capacidade de gerar modelos 3D paramétricos, com a produção de documentação (vistas ortográficas), detalhes e cronogramas, adicionando inteligência ao modelo como um instrumento de gerenciamento de conservação do patrimônio; em oposição aos modelos 3D sofisticados, criados apenas para visualização.

Paralelamente, outros autores exploraram novos métodos e tecnologias, reiterando a relevância do método HBIM na reengenharia de edifícios históricos, como um instrumento de apoio ao processo de gerenciamento na fase de uso e operação e sua conservação (BRUMANA, 2016; PALOMAR et al., 2018; BRUSAPORCI; MAIEZZA; TATA, 2018).

Nessa linha do tempo de evolução tecnológica e conceitual, observa-se que o acrônimo HBIM também passou por alterações. Inicialmente foi definido como Historic Building Information Modelling (MURPHY; MCGOVERN; PAVIA, 2007, 2009, 2013; BARAZZETTI; BANFI; BRUMANA, 2016; BRUSAPORCI, MAIEZZA, TATA, 2018), passando recentemente a ser designado também como Heritage Building Information Modelling (PALOMAR et al., 2018; 2020; LOPEZ et al., 2018; COUNSELL; ARAYICI, 2017). Em inglês, o termo Heritage (Patrimônio) possui significado mais amplo do que o termo Historic (Histórico), pois inclui políticas de conservação e valores, como os "edifícios altamente protegidos que requerem projetos de intervenção mais profundos e um gerenciamento cuidadoso do ciclo de vida" (PALOMAR et al., 2018, p. 19). De acordo com Bruno, de Fino e Fatiguso (2018), a evolução do termo ocorreu devido à necessidade de complementar a abordagem de "modelagem" com a de "gerenciamento" de informações sobre o patrimônio.

$\mathrm{Na}$ literatura também se encontra o acrônimo BHIMM (Built Heritage Information Modelling/Management ou Modelagem e Gerenciamento de Informações sobre o Patrimônio Construído), adotado pela Universidade de Brescia e pelo Programa de Pesquisa Italiano de Interesse Nacional - PRIN (CIRIBINI; VENTURA; PANERONI, 2015, p. 266). Há, ainda, a designação genérica de "BIM para edifícios existentes", que não envolve apenas os edifícios históricos e culturais (VOLK; STENGEL; SCHULTMANN, 2014). Porém, não há uma regulamentação sobre o uso deste ou daquele termo como o correto ou o mais adequado, o que levou a Historic England (2018) a adotar historic ou heritage com significado indistinto na publicação "Bim for Heritage - Developing a Historic Building Information Model'.

\section{SOBRE A MODELAGEM DE ELEMENTOS HISTÓRICOS EM BIM: GEOMETRIA, INFORMAÇÕES E LIMITAÇÕES}

O BIM surgiu com foco no projeto e construção de novos edifícios, com ferramentas de objetos simples, regulares e padronizados e, por essa razão, a reconstrução virtual e detalhada de edifícios histórico-culturais revelou limitações com uso do software, como indisponibilidade de bibliotecas de componentes paramétricos e ferramentas para modelagem de formas complexas e irregulares, incapazes de interpolar os pontos das digitalizações $3 \mathrm{D}$ em forma de nuvens de pontos, capturadas com ferramentas de escaneamento a laser (LÓPEZ et al., 2018; BRUSAPORCI; MAIEZZA; TATA, 2018). Para Banfi (2017), a primeira restrição do BIM para edifícios históricos está na ausência de objetos 3D complexos, como abóbadas, paredes irregulares, arcos, pilares e decorações nos bancos de dados; a segunda é a sua incapacidade de construção de elementos tal qual nos softwares de modelagem pura, em que é possível definir $N U R B S^{1}$ para gerar entidades tridimensionais complexas, sem investir em longas fases de modelagem. Em um exemplo mais específico, Palomar et al. (2020) relataram dificuldades na modelagem das curvaturas e patologias das paredes, bem como de cornijas e elementos decorativos.

Apesar de grande parte dos estudos apresentarem uma definição de HBIM associada a ferramentas de captura, como escaneamento a laser, Groetelaars (2015) indica que o processo de criação de modelos HBIM 
também pode ser realizado por meio de informações de projetos existentes, ou por levantamento cadastral e medição direta. A autora destaca, também, que a limitação desses métodos pode ocorrer em casos de formas complexas e irregulares, e que as "nuvens de pontos" permitem acelerar o processo de aquisição dos dados geométricos e aumentar a precisão, no entanto, na maioria das vezes esses dados são usados apenas como referência para a geração de desenhos, a conferência de dados existentes ou a modelagem de partes mais complexas da edificação.

Uma série de tecnologias que auxiliam na aceleração da modelagem BIM de edifícios construídos a partir de nuvens de pontos, tais como, entre outros: (i) o EdgeWise e o ClearEdge 3D, que reconhece e gera faces de forma automática permitindo importação para uso como referência na modelagem BIM; (ii) o CloudWorks (Kubit), Virtusurv (Leica) e as novas versões do ScanToBim que, além da importação direta da nuvem de pontos para o Revit, permite mais possibilidades de manipulação e modelagem sobre elas; (iii) o Autodesk Recap Pro, que importa, manipula e exporta a nuvem para outros programas.

No entanto, nenhuma dessas tecnologias apresenta recursos para modelar formas complexas e irregulares de maneira facilitada, a partir de dados brutos da nuvem (GROETELAARS, 2015). Grande parte dos trabalhos que buscam esse reconhecimento automatizado são promissores, mas ainda não apresentam soluções completas para essa finalidade. As abordagens até então incluem estratégias de modelagem semi automática e manual (FAl; RAFEIRO, 2014) e extração de superfícies, planos, vetores 3D ou um subconjunto da nuvem original, que são convertidos em componentes paramétricos com informações estruturadas e que precisam ser executadas manualmente (DORE; MURPHY, 2017). Paralelamente, a manipulação da nuvem é considerada trabalhosa, pois resulta em arquivos pesados, exigindo máquinas robustas, caras e que demandam muito tempo em seu manuseio (MURPHY; MCGOVERN; PAVIA, 2007; CUPERSCHMID; FABRICIO; FRANCO JR., 2019).

Brumana et al. (2019) afirmam que a utilização do HBIM para a representação da complexidade do patrimônio arquitetônico e de seus componentes ainda carece de protocolos e especificações. A fase prática de modelagem no HBIM é de responsabilidade única dos profissionais envolvidos em sua concepção. Um dos grandes desafios na reconstrução dos projetos históricos é a modelagem dos elementos que constituem o modelo virtualmente, as chamadas "famílias" paramétricas.

O termo "famílias" no contexto BIM refere-se, além da representação gráfica de uma classe de objetos ou componentes, aos parâmetros para informações semânticas (fabricante, modelo, custo) e geométricas dos mesmos (BRACHT, 2018). De acordo com Eastman et al. (2014, p.13), "componentes de construção são representações digitais inteligentes (objetos) que 'sabem' o que eles são, e que podem ser associados com atributos (gráficos e de dados) computáveis e regras paramétricas". Os autores também denominam esses elementos de BEM (Building Element Models), que são paredes, pisos, telhados, portas, janelas, equipamentos, mobiliário, entre outros. A parametrização é a propriedade central que distingue o BIM de objetos 3D convencionais, pois define inúmeras relações entre o modelo virtual, a documentação e o edifício construído. Consiste em associar definições geométricas a dados e regras, possibilitando alterações automáticas, com indicação da violação dos parâmetros e com habilidade de vincular-se a receber ou exportar os conjuntos dos seus atributos.

Grande parte das famílias que compõem um modelo virtual de um edifício ainda é genérica, ou seja, não possuem propriedades específicas e detalhes construtivos fiéis ao modelo real, conforme já relatado. Apenas uma pequena parcela de fabricantes atuantes no mercado da construção disponibiliza seus produtos como famílias BIM, presentes em repositórios específicos das indústrias ou em bibliotecas públicas. Para Eastman et al. (2014), o conhecimento conquistado pelas modelagens presentes nessas bibliotecas se tornará uma questão estratégica, representando as melhores práticas, a partir das experiências e informações adquiridas. A tendência é a diminuição de erros e omissões, ampliando a qualidade a partir de novas experiências.

De fato, o desenvolvimento e a administração de famílias é um dos desafios atuais para o setor, devido ao grande número de objetos necessários em uma biblioteca. Em se tratando de componentes HBIM, sua disponibilização torna-se ainda mais difícil. As famílias de elementos históricos, por serem únicas e exclusivas, não estão presentes em bibliotecas ou repositórios e não interessam ao mercado enquanto produto comercializável. Isso exige que o projetista domine as regras de modelagem para documentar o patrimônio edificado em BIM. Muitos desses componentes de edifícios históricos possuem geometria complexa e, em alguns casos, necessitam, além de equipamentos especiais para captura de sua forma, um conhecimento de modelagem de famílias ainda de pouco domínio e difusão, considerando os softwares mais conhecidos do mercado, como o Revit da fabricante Autodesk, e o Archicad, da Graphisoft. Além disso, o elemento paramétrico normalmente exige vínculos a fontes de dados externos.

Paralelamente à reconstrução morfológica dos elementos, é necessária sua integração a um sistema ontológico de informações sobre a edificação (SIMEONE et al., 2014) e a um banco de dados organizados 
sobre o modelo HBIM (INZERILLO et al., 2016). Alguns estudos discutem a dificuldade de documentar corretamente os edifícios históricos e os desafios na participação de uma equipe multidisciplinar, formada por especialistas de áreas não técnicas e técnicas, como historiadores, restauradores, gerentes de monumentos, arquitetos, engenheiros e arqueólogos. Em parte, essa dificuldade está relacionada ao tempo prolongado de uso que o edifício histórico normalmente possui, às prováveis alterações de suas características ao longo de várias fases histórico-construtivas, o que inclui patologias, reaproveitamento de materiais (PALOMAR et al., 2020) e à dificuldade de se obter dados confiáveis sobre o edifício.

Um projeto em BIM constitui-se por representações gráficas tridimensionais de elementos (paredes, portas, janelas, entre outros), que são associados a informações semânticas sobre esses elementos (medidas, materiais, custos, fornecedores). É possível que a representação gráfica de um elemento, quando verificada isoladamente, sugira uma precisão ou intenção maior que a de fato realizada. Por isso, no processo de modelagem BIM é necessário definir o nível de informação e de representação gráficas do modelo ou elemento, considerando as fases do seu desenvolvimento. Tendo em vista essa necessidade, foi criado o conceito de LOD (Level of Development) ou Nível de Desenvolvimento para fornecer sistematicamente o nível de confiança que pode ser associado a um elemento (BIMFORUM, 2019).

Segundo Van Berlo e Bomhof (2014), a introdução do conceito de LOD é dada em 2004, pela empresa Vico Software, com a definição de MPS (Model Progression Specification), visando facilitar o gerenciamento de informações. O MPS tinha como base a definição do Nível de Detalhe, uma descrição das etapas de progressão de um elemento BIM, indo do nível mais baixo (100, aproximação apenas conceitual) ao mais alto (400, alta precisão representacional), e conforme construído (nível 500). Posteriormente, outros países também publicaram suas diretrizes, como a Dinamarca, em 2006; os Estados Unidos (2010), com o mesmo modelo adotado pela Austrália (2013), além de outras formas de aplicações independentes.

Visando aprimorar e padronizar o conceito, em 2008 o Instituto Americano de Arquitetos (AIA) publicou o Protocolo AIA-e202-2008. Desde o ano de 2013, esse documento vem passando por atualizações periódicas, com discussões de agentes do setor da AECO (Arquitetura, Engenharia, Construção e Operação) por meio do BIMForum². A edição de 2019 define Nível de Desenvolvimento (LOD) como "uma referência que permite aos profissionais do setor de AECO especificar e articular com alto grau de clareza o conteúdo e a confiabilidade dos BIMs (Building Information Models) em vários estágios do projeto e processo de construção" (BIMFORUM, 2019, p. 4). Van Berlo e Bomhof (2014) observam que o termo LOD alterou de "detalhe", dado inicialmente, para "desenvolvimento", evoluindo posteriormente para nível de "confiança ou credibilidade", tornando "geometria" e "informação" igualmente importantes.

Desta forma, os agentes do setor e o BIMForum criaram uma força-tarefa multidisciplinar para desenvolver e manter a especificação de LOD, com seus instrumentos disponibilizados em uma plataforma virtual. Trata-se de uma coleção organizada de interpretações das definições de LOD do AIA, que descreve os requisitos de entrada e fornece exemplos gráficos dos diferentes níveis de desenvolvimento de uma ampla variedade de classes de elementos de construção. Atualmente, a especificação LOD está estabelecida entre os níveis 100 a 400, acrescido do nível 350, para melhor atender aos níveis de informações necessários para uma coordenação eficaz. Embora apresente o LOD 500, a especificação considera que esse nível está relacionado à verificação em campo de um projeto já construído e por isso não indica seu nível (BIMFORUM, 2019).

Dentre as diferentes definições, a modelagem de edifícios históricos pela metodologia BIM encontra limitações para estabelecer sua classificação apropriada pelo sistema LOD atual (FAl; RAFEIRO, 2014). Brumana et al. (2019) relata que uma das dificuldades na modelagem é a ausência de especificação sobre a precisão e o nível da geometria necessária para o modelo de cunho histórico. De acordo com Banfi (2017), a classificação não atende porque elementos históricos dependem de instrumentos específicos de captura e de ferramentas externas para a geração das formas que não estão presentes no sistema BIM, como os softwares de modelagem pura e técnicas de modelagem avançadas, que apresentam um número significativo de diferenças, como geometrias primitivas, lógica construtiva, linguagem de modelagem e diversos formatos de troca ( $d x f, d w g, s k p, p l n, 3 d m, d g n, r v t)$, que resultam no crescimento exponencial da análise baseada em BIM, além da dependência das informações registradas/documentadas do patrimônio a ser modelado.

A ausência de uma especificação para elementos "as is model", como o modelo construído, fez surgir a necessidade de uma definição de níveis de desenvolvimento para edificações de valor histórico-cultural, a fim de garantir níveis de confiabilidade nos elementos modelados. Brumana et al. (2019) apresentam o conceito de LOG (Level of Geometry), em que uma classificação em cinco níveis é estabelecida: LOG 100 - são desenhos bidimensionais; LOG 200 - estágio de aquisição de dados por técnicas de fotogrametria; LOG 300 - modelo com precisão geométrica; LOG 400 - fase generativa por nuvens de pontos com alta precisão; LOG 500 - altos níveis de compartilhamento das informações. Um exemplo desse alto grau de compartilhamento de informações é apresentado por Palomar et al. (2020), por meio de uma plataforma online HBIM - que reúne informações unificadas sobre o patrimônio e capacidade de sincronização com o modelo BIM. 
No Brasil, ações vêm sendo desenvolvidas para estimular e ampliar o uso do BIM. Integra essas ações, os decretos № 9.983, que dispõe sobre a Estratégia Nacional de Disseminação e institui o Comitê Gestor da Estratégia do BIMBR, que visa disseminar e promover o uso da tecnologia no país (BRASIL, 2019); e № 10.306, que regulamenta a utilização do BIM pelos órgãos e pelas entidades da administração pública federal (BRASIL, 2020); e ainda, o desenvolvimento da Biblioteca Nacional BIM, com a disponibilização de famílias em repositórios públicos, organizados por categoria, tipo de software, além de normas e manuais. Antes mesmo destes decretos, a Fundação para o Desenvolvimento da Educação (FDE) ${ }^{3}$ e o Programa Minha Casa Minha Vida (PMCMV) 4 também haviam disponibilizado bibliotecas. Apesar dessas ações, o desenvolvimento não atende à necessidade dos elementos históricos, carecendo de processos e orientações aos profissionais.

A limitação da modelagem em BIM para edifícios existentes motivou esta pesquisa. O objetivo é desenvolver um elemento de uma edificação histórica modernista por meio do HBIM, com foco no seu registro e documentação, buscando analisar os recursos de modelagem e resultados alcançados para a arquitetura de geometria regular. O elemento modelado foi a escada externa do Edifício E1, o primeiro prédio construído no campus da Universidade de São Paulo (USP), na cidade de São Carlos, entre os anos de 1954 e 1957. O E1 é um edifício típico da arquitetura modernista brasileira, concebido para ser reproduzido como padrão para os demais edifícios do campus da universidade, o que deu origem ao seu nome. Foi projetado em coautoria pelo arquiteto Hélio de Queiroz Duarte (1906-1989) e pelo engenheiro Ernest de Carvalho Mange (19222005), sendo caracterizado como um bloco laminar que sustenta três pavimentos tipo sobre pilotis, totalizando área de $3.400 \mathrm{~m}^{2}$ (Figura 1).

Figura 1: Vistas externas do edifício E1.

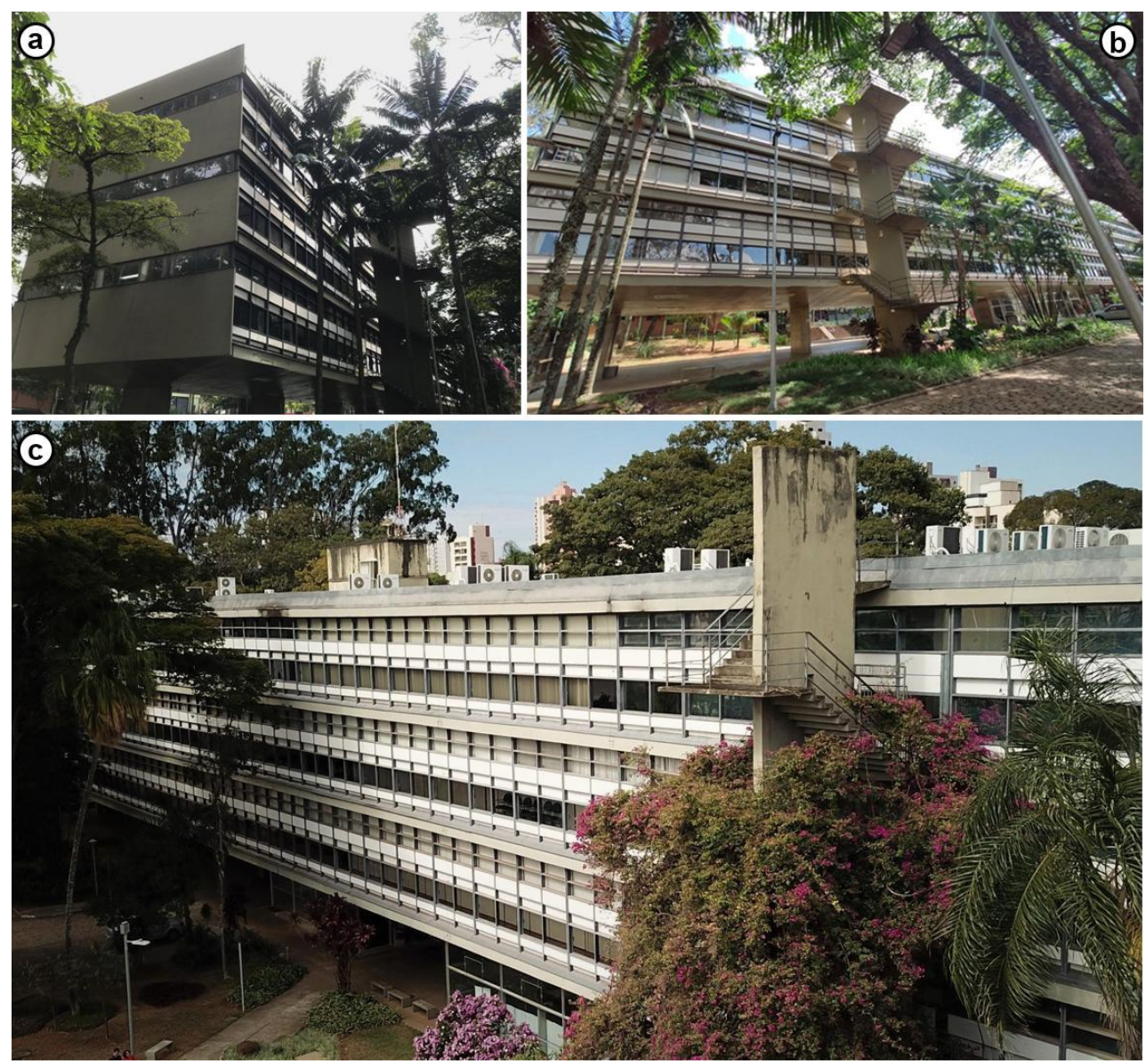

Fonte: Fotos (a) e (b), autores; Foto (c) de Júlio César Franco Júnior.

Sob influência de Le Corbusier, com quem Mange fez estágio no ATBAT - Atelier de Batusseurs, o edifício segue os cinco pontos da arquitetura moderna e possui como referência as soluções técnicas do Pavilhão Suíço (1930-1932), como as instalações concentradas em uma canaleta visitável junto ao eixo longitudinal, que desce das lajes aos pilares centrais; e também da Unidade de Habitação de Marselha, sendo sua principal inspiração a parede cortina em aço, elemento de composição que promove ritmo às fachadas (NOBRE, 2007). Paralelamente, o edifício também teve como pauta de projeto ser racional, funcional, flexível, possibilitar a 
integração social e cultural, além do emprego de tecnologia moderna, como concreto armado, aço, vidro, entre outros, em sua construção (NOSELLA; BUFFA, 2000).

Por questões orçamentárias, o projeto não foi replicado e atualmente figura como único exemplar, com valor histórico pela concepção do projeto, soluções construtivas de caráter modernista e pelo pioneirismo no emprego da coordenação modular no Brasil (NOBRE, 2007). Ao longo de seus mais de 60 anos, o E1 já passou por algumas intervenções técnicas e funcionais. Entre as técnicas, perdeu seu "teto jardim" e teve suas instalações de lógica e elétrica ampliadas e atualizadas. Alterações que solicitam um registro do seu estado atual, como subsídio às futuras. Funcionalmente, já abrigou salas de aula, sendo atualmente o prédio administrativo do campus.

\section{Processo de Modelagem de Componentes BIM aplicado a um edifício histórico moderno}

Todo projeto de reconstrução arquitetônica histórica deve partir de um planejamento global, em que os produtos resultantes variam em função das necessidades, objetivos e tecnologias empregadas (AMORIM, 2011). Desta forma, a modelagem HBIM deve ser orientada pelo uso pretendido do modelo, podendo este ser elaborado para fins de "documentação, avaliação de propostas de intervenção, gestão do patrimônio, entre outros" (CUPERSCHMID; FABRICIO; FRANCO JR., 2019).

O processo de documentação do E1 sob o conceito de BIM foi iniciado em 2017, a partir de estudos do grupo de pesquisa Arquitec (FIALHO; COSTA; FABRICIO, 2018), do curso de pós graduação do Instituto de Arquitetura e Urbanismo (IAU), da USP de São Carlos (SP), com o propósito de testar ferramentas, ampliar conhecimento sobre BIM, além de contribuir com registro para apoiar futuras intervenções no patrimônio. Até então, os componentes foram elaborados visando uma reprodução geométrica simplificada, sem perder a sua capacidade paramétrica. Por isso, alguns elementos de geometria mais complexa, foram modelados com objetos da própria biblioteca de famílias do Revit, sem uma acuidade e refinamento dos detalhes, como no caso das escadas externas do edifício.

O E1 possui duas escadas externas idênticas, consideradas elementos de destaque na composição da estética da fachada do edifício, juntamente com a parede cortina de vidro já modelada em BIM anteriormente. Foi selecionada a escada do lado esquerdo, considerando a vista frontal da fachada norte. A seleção da escada como objeto neste estudo justifica-se pela sua arquitetura moderna, em linhas retas, mas que representam uma complexidade formal em seu conjunto: degraus dentados; base do patamar em forma de uma pirâmide invertida, com ângulos que traduzem bem o lema modernista "a forma segue a função". A forma remete ao desenho da laje do primeiro piso, criando uma identidade visual, ao mesmo tempo em que possui a função de facilitar o escoamento das águas de chuva, atuando como pingadeira. Imagina-se que esse desenho, moldado em concreto armado, representou um desafio à época de sua construção, o que reitera o interesse pela sua reconstrução em BIM.

Desta forma, a modelagem que se propõe neste estudo busca reproduzir o modelo "as is" detalhado da escada do E1, como registro/documento mais fiel ao elemento construído, com maior nível de confiança, explorando as funcionalidades do software Revit, principalmente relativas à sua capacidade paramétrica, a fim de reproduzir o mesmo modelo à segunda escada externa do projeto. Também irá compor uma biblioteca de famílias HBIM, em desenvolvimento, para apoiar futuros projetos de intervenções no E1 e atuar como referência a outros pesquisadores e profissionais do setor.

Este processo também visa identificar os recursos disponíveis para uma modelagem no Revit, porém de uma forma mais livre do que a dos modelos preexistentes nas bibliotecas; além de permitir analisar-se os resultados quanto à capacidade de reprodução dos documentos, à manutenção da sua capacidade paramétrica, ao esforço empreendido em termos de recursos e de tempo empregado, com destaque para suas potencialidades e limitações.

Os recursos tecnológicos empregados foram o software Revit (versão educacional, 2019 - Autodesk), trena métrica em fita de aço, smartphones para gerar a fotogrametria com uso de aplicativo, registro fotográfico e anotações simples. A equipe é formada por dois arquitetos, dois estudantes de graduação em arquitetura e um engenheiro civil.

Considera-se este processo como de documentação intermediário. Ela visa servir de base para trabalhos futuros do grupo de pesquisa Arquitec da USP São Carlos, que buscará maiores investimentos tecnológicos a fim de realizar um registro mais amplo do Edifício E1. Estima-se que tais trabalhos terão abordagem no reconhecimento de estrutura interna da edificação, identificação de patologias, alterações realizadas ao longo do ciclo de uso, a fim de contribuir para um efetivo gerenciamento desse patrimônio. Para tanto, buscará contribuições de profissionais de áreas não técnicas, conforme trabalhos correlatos. 


\section{MÉTODO E MATERIAIS}

Vários estudos descrevem processos para a documentação do patrimônio histórico por meio do HBIM (FAI; RAFEIRO, 2014; CIRIBINI; VENTURA; PANERONI, 2015; BRUSAPORCI; MAIEZZA; TATA, 2018), que foram utilizados como referências para o planejamento metodológico da pesquisa em questão. Desta forma, o método foi realizado obedecendo a quatro etapas (Revisão, Coleta de Dados, Modelagem e Avaliação), conforme demonstra a Figura 2.

Figura 2: Etapas do Método.

\begin{tabular}{|c|c|c|c|}
\hline $\begin{array}{l}\text { ETAPA } 1 \\
\text { Revisão }\end{array}$ & $\begin{array}{l}\text { ETAPA } 2 \\
\text { Coleta de Dados }\end{array}$ & $\begin{array}{l}\text { ETAPA } 3 \\
\text { Modelagem }\end{array}$ & $\begin{array}{l}\text { ETAPA } 4 \\
\text { Avaliação }\end{array}$ \\
\hline $\begin{array}{l}\text { BIM } \\
\text { HBIM } \\
\text { BEM's }\end{array}$ & $\begin{array}{l}\text { Registro } \\
\text { Fotográfico } \\
\text { Levantamento } \\
\text { no Local }\end{array}$ & $\begin{array}{l}\text { Famílias de } \\
\text { Sistemas, } \\
\text { Carregáveis e } \\
\text { no Local }\end{array}$ & $\begin{array}{l}\text { Aplicação } \\
\text { Famílas no } \\
\text { Modelo BIM } \\
\text { Existente }\end{array}$ \\
\hline
\end{tabular}

- Na Etapa 1 foi realizada cuidadosa revisão bibliográfica voltada à aplicação do BIM ao patrimônio, conceito referenciado como HBIM (Heritage Building Information Modelling) e, especificamente, estudos sobre modelagem de famílias nos softwares BIM.

- Na Etapa 2, foram levantadas informações sobre o projeto original da escada do edifício em estudo (Figura 3), fotografias e medições no local com o uso de trena métrica em fita de aço. Como parte dos levantamentos no local, também foi realizado uma documentação fotogramétrica por meio do uso de um aplicativo ${ }^{5}$ para smartphone capaz de gerar uma nuvem de pontos tridimensional da escada, a fim de auxiliar na captura de informações para modelagem do elemento estudado. A altura do elemento e o entorno arborizado dificultam a captura e o processamento de imagens para fotogrametria. Por isso, foram produzidas nuvens de pontos de partes específicas e mais relevantes para a obtenção de informações que pudessem auxiliar na modelagem do elemento (Figura 4). Embora tenha sido realizada com equipamento de baixo custo, a nuvem de pontos fornece informações de profundidade e visualização que poderiam não ser captadas em fotografias convencionais em duas dimensões. A maior parte dos softwares de modelagem aceita a inserção deste tipo de arquivo no modelo BIM para auxiliar a conferência sobre aspectos de dimensionamento, proporção e representações visuais.

- Na Etapa 3, foram realizados testes de possíveis formas para modelagem BIM da escada em estudo. Para tanto foi utilizado o software Revit da Autodesk, em sua versão 2019 com licença educacional. De acordo com a Autodesk (2019) há três tipos de famílias no software usadas para criação de modelos BIM, são elas: famílias de sistema, famílias carregáveis e famílias no local, cujas principais características são apresentadas no Quadro 1.

A maioria das famílias utilizadas nos projetos faz parte de duas categorias: (i) as famílias de sistemas, que estão hospedadas no software; e (ii) as famílias carregáveis, que podem ser obtidas pelos fabricantes ou em bibliotecas de modelos BIM. A ausência do terceiro tipo, as famílias no local, se deve ao fato de seu uso demandar um grande esforço de modelagem dos elementos que as compõem, dependendo fortemente da complexidade da geometria e da qualidade das informações desejáveis. Para tanto, conforme a orientação do fabricante do software - a AUTODESK (2019) -, os elementos "fora do padrão" ou personalizados devem ser criados utilizando as famílias no local. No entanto, essa determinação cria a limitação de não compartilhamento do elemento, uma vez que o mesmo é criado dentro de um projeto integrado a ele, sem um padrão específico e próprio. 
Figura 3: Projeto original da escada do edifício E1 - USP São Carlos.

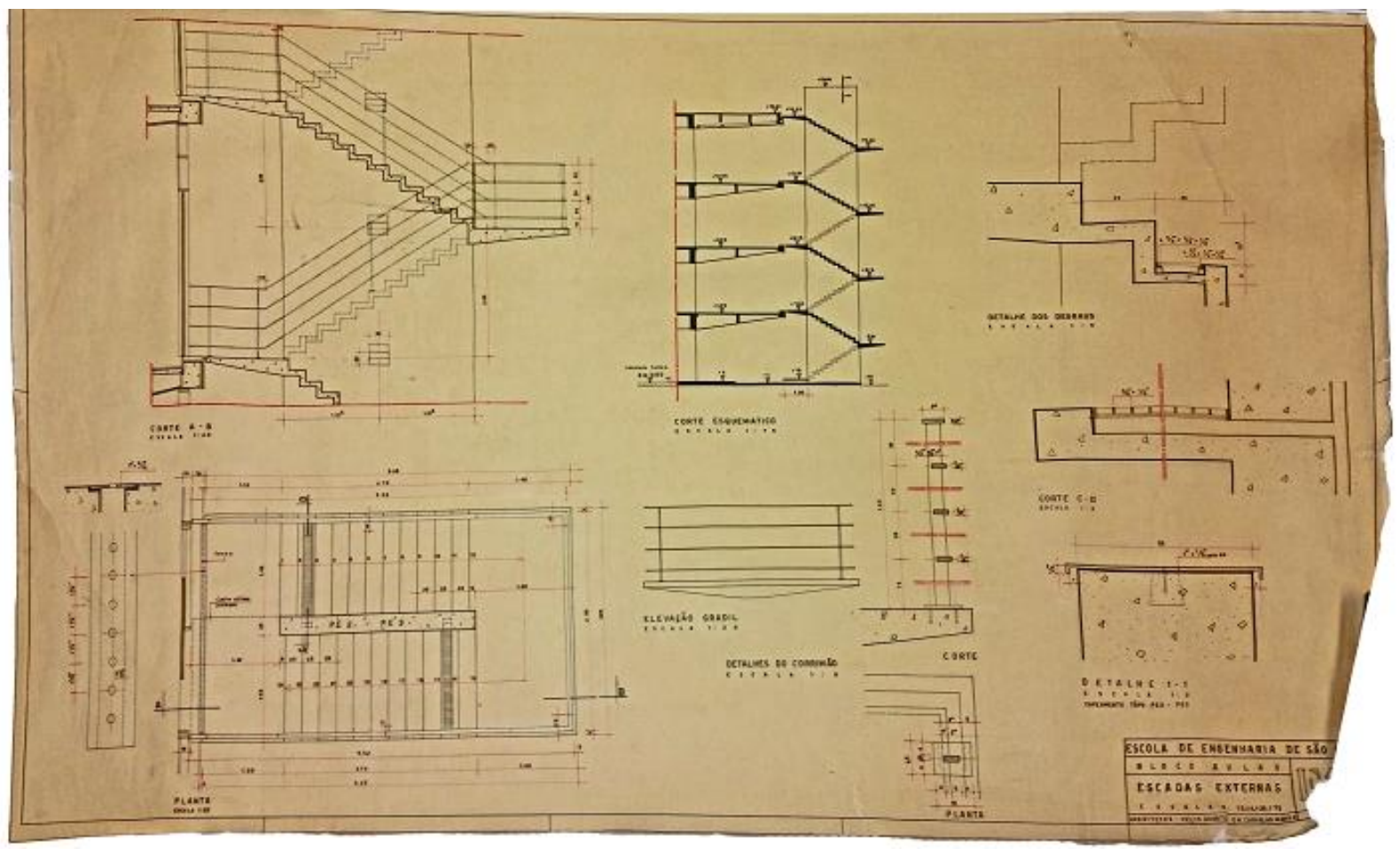

Fonte: Prefeitura do campus USP de São Carlos (2017).

Figura 4: Nuvem de pontos por Fotogrametria de parte da escada do edifício E1.

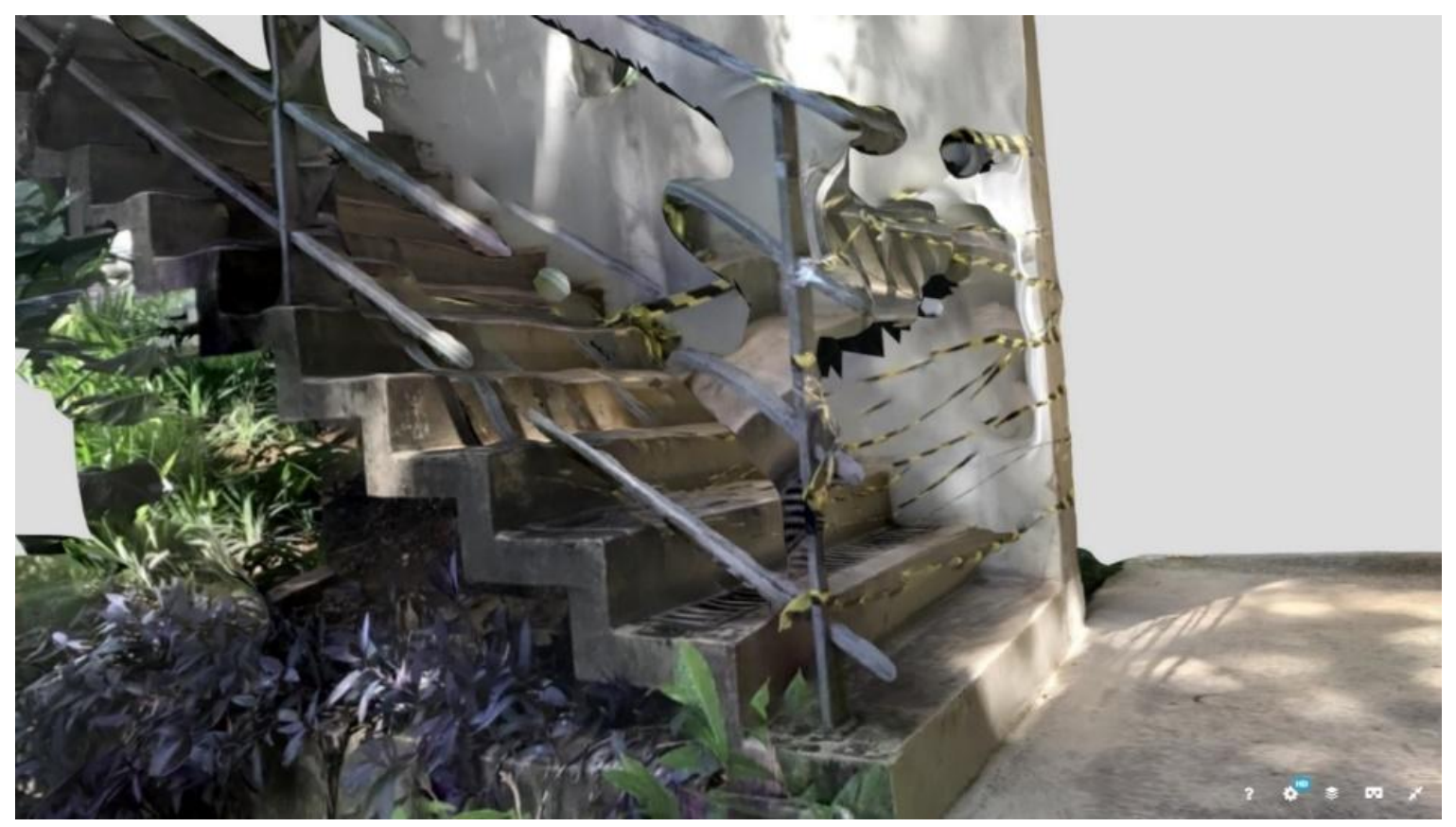

Fonte: Os autores. 
Quadro 1: Características das Famílias BIM no software Autodesk Revit.

\begin{tabular}{|c|c|c|}
\hline Tipo & Descrição & Componentes \\
\hline $\begin{array}{l}\text { Famílias de } \\
\text { Sistema }\end{array}$ & $\begin{array}{l}\text { São predefinidas, com limitações nas possibilidades de } \\
\text { alteração. Parâmetros fixos, sem possibilidade de adição de } \\
\text { novos ou exclusão dos existentes. Constituem configurações de } \\
\text { sistema que compõem a maioria dos projetos desenvolvidos no } \\
\text { software. Neste tipo de família não é possível salvar o arquivo } \\
\text { fora do software de origem para o uso em outra finalidade. } \\
\text { Também não é possível criar "do zero" ou excluir uma família de } \\
\text { sistema, apenas duplicá-las para modificar alguns parâmetros e } \\
\text { gerar certo grau de personalização. Não é possível hospedar } \\
\text { outros tipos e elementos para compor famílias personalizadas. }\end{array}$ & $\begin{array}{l}\text { Elementos de configuração que } \\
\text { afetam o ambiente de projeto } \\
\text { como níveis, eixos, folhas de } \\
\text { desenho técnico, janelas com } \\
\text { vistas (viewports). Elementos } \\
\text { básicos da construção como } \\
\text { paredes, telhados, lajes, pisos, } \\
\text { escadas e dutos. }\end{array}$ \\
\hline $\begin{array}{l}\text { Famílias } \\
\text { Carregáveis }\end{array}$ & $\begin{array}{l}\text { Estas são altamente modificáveis devido à variedade de } \\
\text { personalização dos produtos disponíveis para a construção civil. } \\
\text { Neles os arquivos possuem extensão "rfa" e podem ser salvos } \\
\text { externamente, separados do arquivo principal do projeto, para } \\
\text { que sejam carregadas de acordo com a necessidade de cada } \\
\text { modelo virtual. A composição pode apresentar diversas } \\
\text { variações dentro de uma mesma família, que são chamados de } \\
\text { tipos. Como exemplo, cria-se uma família de janela de correr e } \\
\text { múltiplos tipos dentro da mesma família como janela de correr } \\
\text { com } 2 \text { folhas, } 3 \text { folhas, } 4 \text { folhas, com variações de acabamentos, } \\
\text { etc. }\end{array}$ & $\begin{array}{l}\text { Elementos de anotação } \\
\text { personalizados para a } \\
\text { representação dos desenhos } \\
\text { técnicos como blocos de } \\
\text { margens, símbolos e carimbos. } \\
\text { Elementos da construção que } \\
\text { possuem características dos } \\
\text { seus fabricantes como: janelas, } \\
\text { portas, mobiliário, dentre outros. }\end{array}$ \\
\hline $\begin{array}{l}\text { Famílias no } \\
\text { Local }\end{array}$ & $\begin{array}{l}\text { São caracterizadas por elementos criados no contexto de um } \\
\text { projeto específico. O princípio de modelagem parte de } \\
\text { geometrias dentro do arquivo de projeto, ajustando as dimensões } \\
\text { de acordo com a necessidade. Quando criadas, o software gera } \\
\text { um elemento no local onde foi modelado, contendo um único tipo } \\
\text { de família. Esse processo exige grande esforço de modelagem } \\
\text { dependendo da complexidade da geometria. É a família mais } \\
\text { usada para elementos que não serão aproveitados } \\
\text { posteriormente em outros projetos, por serem modelados } \\
\text { relacionando-se com elementos de um projeto atual. Não são } \\
\text { famílias compartilháveis externamente. }\end{array}$ & $\begin{array}{l}\text { Qualquer elemento com } \\
\text { características únicas dentro de } \\
\text { um projeto como: como exemplo, } \\
\text { um conjunto de prateleiras que } \\
\text { preenchem um espaço entre } \\
\text { paredes. }\end{array}$ \\
\hline
\end{tabular}

Fonte: Os autores com base em Autodesk (2019).

De acordo com as definições anteriores, uma escada é considerada um tipo de família de sistema. Este tipo de família possui restrições paramétricas quanto à geometria, posicionamentos e associações com outros elementos, pois seus parâmetros são predefinidos e salvos em modelos e projetos, não sendo carregáveis a partir de arquivos externos (AUTODESK, 2019). Por isso, não é possível criar, copiar ou excluir famílias de sistema. A opção para o usuário é duplicar e modificar os atributos de uma família existente e assim "criar" suas próprias famílias personalizadas.

No software Revit, as famílias são criadas a partir de templates, que são arquivos configurados para permitir a modelagem específica de elementos paramétricos por categorias ${ }^{6}$ e compartilháveis. No entanto, esses templates são usados para criação de famílias carregáveis e no local, o que impõe uma limitação na criação e na modelagem de elementos que fogem ao padrão do que é trazido nas bibliotecas Revit para famílias de sistema.

A escada do edifício $\mathrm{E} 1$, objeto da modelagem, apresenta um desenho específico e autoral, pois possui características do tipo dentada (Figura 5a), compreendendo degraus e espelhos recortados e patamar com a base inferior em formato piramidal (conforme Figura $5 \mathrm{~b}$ e $5 \mathrm{c}$ ). A peculiaridade de tais características gera dificuldades para a modelagem de uma família que não obedece ao padrão geométrico do elemento escada pré existente no software BIM, isso levou os autores a testarem as possibilidades oferecidas pelo software.

Com bases nas considerações anteriores, o objeto de estudo (a escada do edifício E1) foi modelado seguindo três processos distintos descritos a seguir: $\left(1^{\circ}\right)$ Processo por Família de Sistema; $\left(2^{\circ}\right)$ Processo por Família Composta; $\left(3^{\circ}\right)$ Processo de Modelagem no Local. 
Figura 5: Vista Superior dos degraus, Vista Inferior do patamar e Vista Inferior dos degraus.
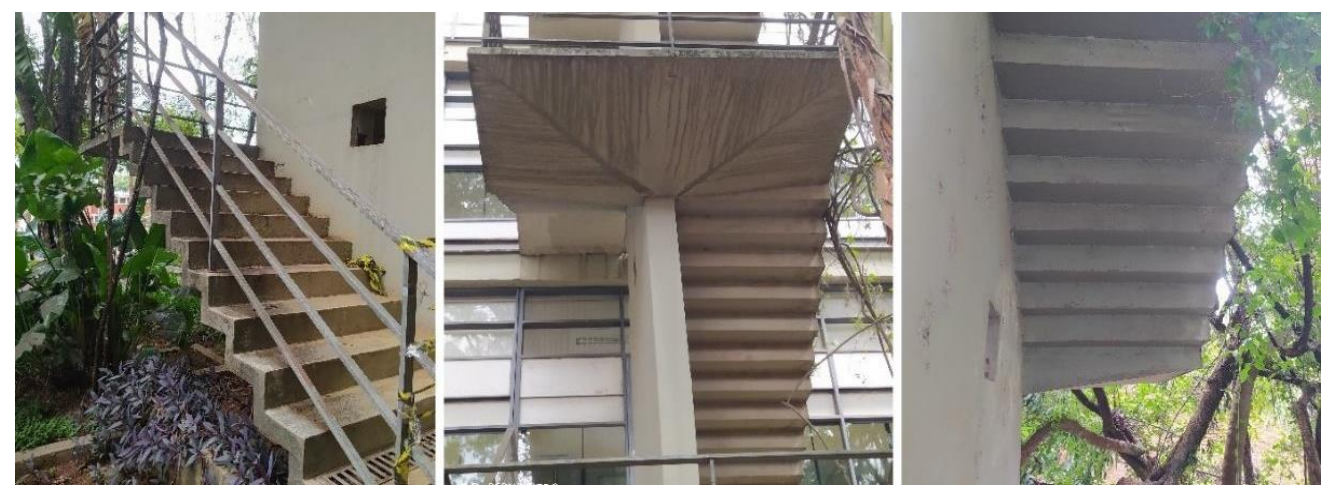

Fonte: Os autores.

\section{$\left(1^{\circ}\right)$ Processo de Modelagem por Família de Sistema}

Este processo é a forma comumente usada para modelar os principais objetos BIM que compõem um projeto de edifício. Neste $1^{\circ}$ processo inicia-se uma Família de Sistema (escada predefinida do tipo monolítica) dentro de um arquivo de template de projeto no Revit (extensão "rte"), para isso, utilizou-se o "modelo de arquitetura" fornecido pelo software. A partir desse arquivo, o elemento foi modelado com base nos níveis dos pavimentos da edificação definidos no projeto original, utilizando a ferramenta escada. Foram redesenhados o croqui dos pisos e espelhos dos degraus, assim como os patamares.

A família da escada monolítica foi duplicada e renomeada, adaptando os parâmetros preexistentes para as dimensões do elemento estudado. Esse tipo de modelagem mantém os aspectos gráficos automatizados para representação do elemento em planta baixa e cortes, o que é desejável para facilitar o processo de documentação do projeto. O software reconhece o modelo como uma escada e conserva propriedades paramétricas importantes como o dimensionamento dos degraus, detalhamento da estrutura e hospedagem do guarda-corpo. No entanto, por se tratar de uma família de sistema, muitos aspectos de personalização necessários para a modelagem correta do elemento não estão disponíveis nesse procedimento. Não há como representar a forma do patamar piramidal nesse caso, e também não há possibilidade de adição de parâmetros para registro de outras informações na família ou representação de qualquer imperfeição que o elemento possa ter para representar o objeto em seu estado atual.

Figura 6: Representação em planta e elevação da escada modelada no $1^{\circ}$ processo.
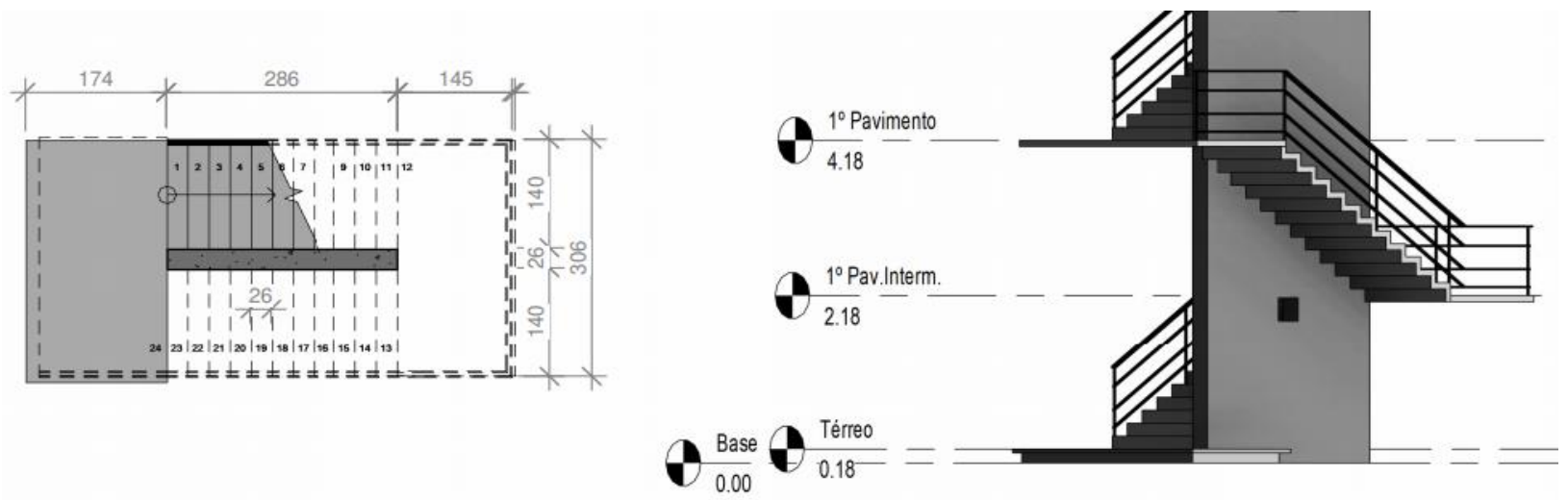

Fonte: Os autores.

\section{$\left(2^{\circ}\right)$ Processo de Modelagem por Família Composta}

Neste segundo procedimento de modelagem, optou-se pela composição de uma família de Sistema para a parte dos degraus da escada e uma Família Carregável para o patamar piramidal, compondo assim o elemento. Inicialmente foi necessária a criação de uma família específica para o patamar em um arquivo de edição de famílias, com extensão "rfa". O arquivo utilizado foi o "Modelo genérico com base em uma face", disponibilizado na biblioteca do Revit. Assim, o patamar foi modelado utilizando a geometria de um 
paralelepípedo com a inserção de parâmetros de largura, comprimento e espessura. Por sua vez, a forma piramidal foi obtida utilizando a ferramenta "formas por vazios", usada para recortar a forma nas dimensões e desenho desejados.

A parte dos degraus da escada (espelhos + pisos) foi modelada como descrito no $1^{\circ}$ procedimento, utilizando uma família de sistema de escada monolítica preexistente no software. Logo após, o arquivo da família do patamar criado anteriormente (com extensão "rfa"), foi carregado no modelo da família de sistema dos degraus da escada, compondo o modelo final deste processo. É importante destacar que na família do patamar é possível acrescentar parâmetros de informações textuais para documentação do elemento, tais como estado de conservação e patologias. O mesmo não acontece na família que corresponde aos lances da escada, por se tratar de uma configuração pré existente do sistema que não aceita a adição ou exclusão de parâmetros.

Figura 7: Modelagem da família que compõe o patamar.
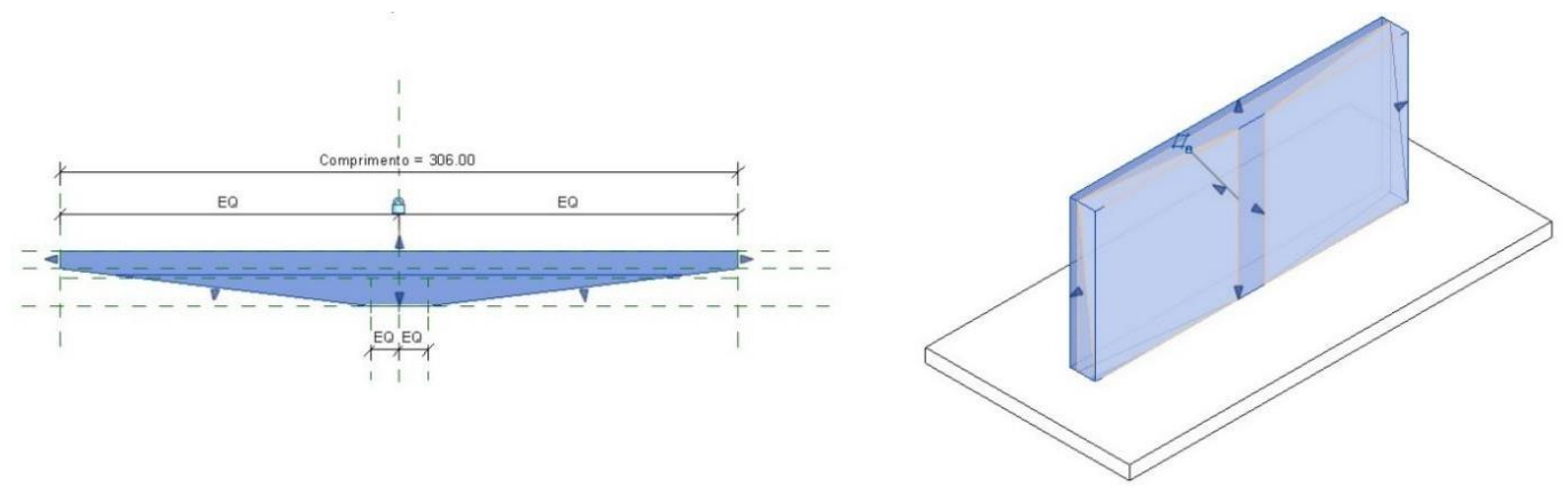

Fonte: Os autores.

Outro problema identificado no processo foi a perda de informação na representação em planta baixa do elemento. Pelo fato de cada lance da escada corresponder a um elemento distinto, o software não consegue gerar a representação da escada de maneira correta em planta baixa, demandado que o projetista faça a representação de forma manual posteriormente, o que não é desejável em um software BIM. Além disso, algumas informações também foram perdidas como a contagem correta do número de degraus e a hospedagem do guarda-corpo de forma automatizada em toda a extensão do elemento. Neste caso, o guardacorpo precisa ser modelado pela ferramenta "desenho do croqui" em toda a extensão da escada, necessitando de ajustes entre lances e patamares, demandando maior esforço de modelagem.

Em ambas as famílias há a possibilidade de preenchimento de um parâmetro URL, que corresponde a um hiperlink que redireciona informação para um endereço eletrônico ${ }^{7}$ contendo informações sobre o edifício estudado (fotos históricas e atuais, diversos relatórios, e uma biblioteca com os próprios modelos BIM desenvolvidos).

\section{$\left(3^{\circ}\right)$ Processo de Modelagem por Família no Local}

No terceiro processo, foi utilizado o tipo família no local, desenvolvendo uma família específica com extensão "rfa" por meio do template "Modelo genérico com base na face" fornecido pelo software. Esse processo é recomendado quando há elementos com formas difíceis de serem encontradas em famílias pré-configuradas. Em visita ao edifício estudado, analisando o modelo gerado na nuvem de pontos por fotogrametria e realizando medições com trena, constatou-se que a escada apresenta pequenas variações nas dimensões dos espelhos e pisos, fato já esperado em se tratando de um edifício histórico, que poderiam ser incorporadas nesse terceiro processo de modelagem.

Para atender as excentricidades de dimensões entre os degraus da escada e ao mesmo tempo otimizar o processo de modelagem, foi criada uma família moldada no local composta de um único lance de escada e um patamar com dimensões associadas a parâmetros isolados (Figura 8). Desse modo, é possível ajustar a dimensão de cada degrau especificamente de acordo com a medida coletada no local para aumentar a precisão das informações do modelo.

Neste procedimento, cada elemento é composto por um lance de escada e um patamar que devem ter as suas dimensões ajustadas conforme medições no local. Cada degrau possui dois parâmetros individuais 
(Espelho $1^{\circ}$ Degrau e Piso $1^{\circ}$ Degrau) que absorvem as variações identificadas no local e aumentam a precisão do modelo (Figura 9). Após esses dimensionamentos, cada lance de escada deve ser duplicado e renomeado, repetindo todo o processo ao longo dos pavimentos do edifício para compor a totalidade da escada.

Figura 8: Vistas da família com degraus de dimensões variáveis (parametrizados).

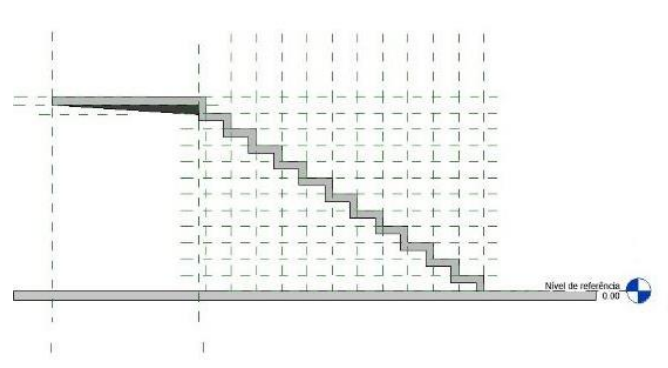

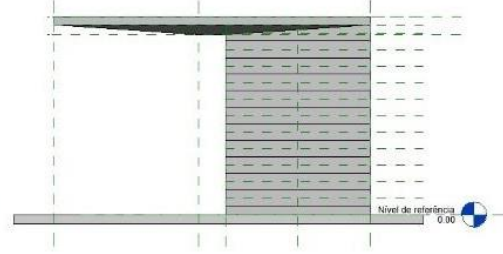

Fonte: Os autores.

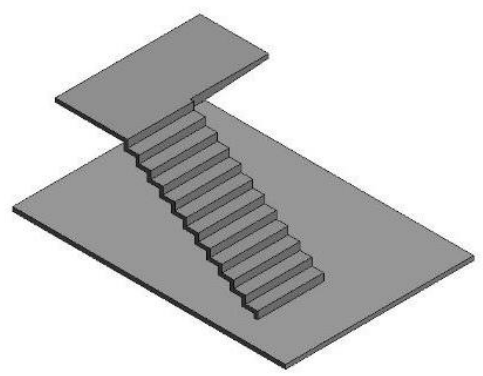

Figura 9: Tabela de parâmetros da escada modelada no $3^{\circ}$ processo.

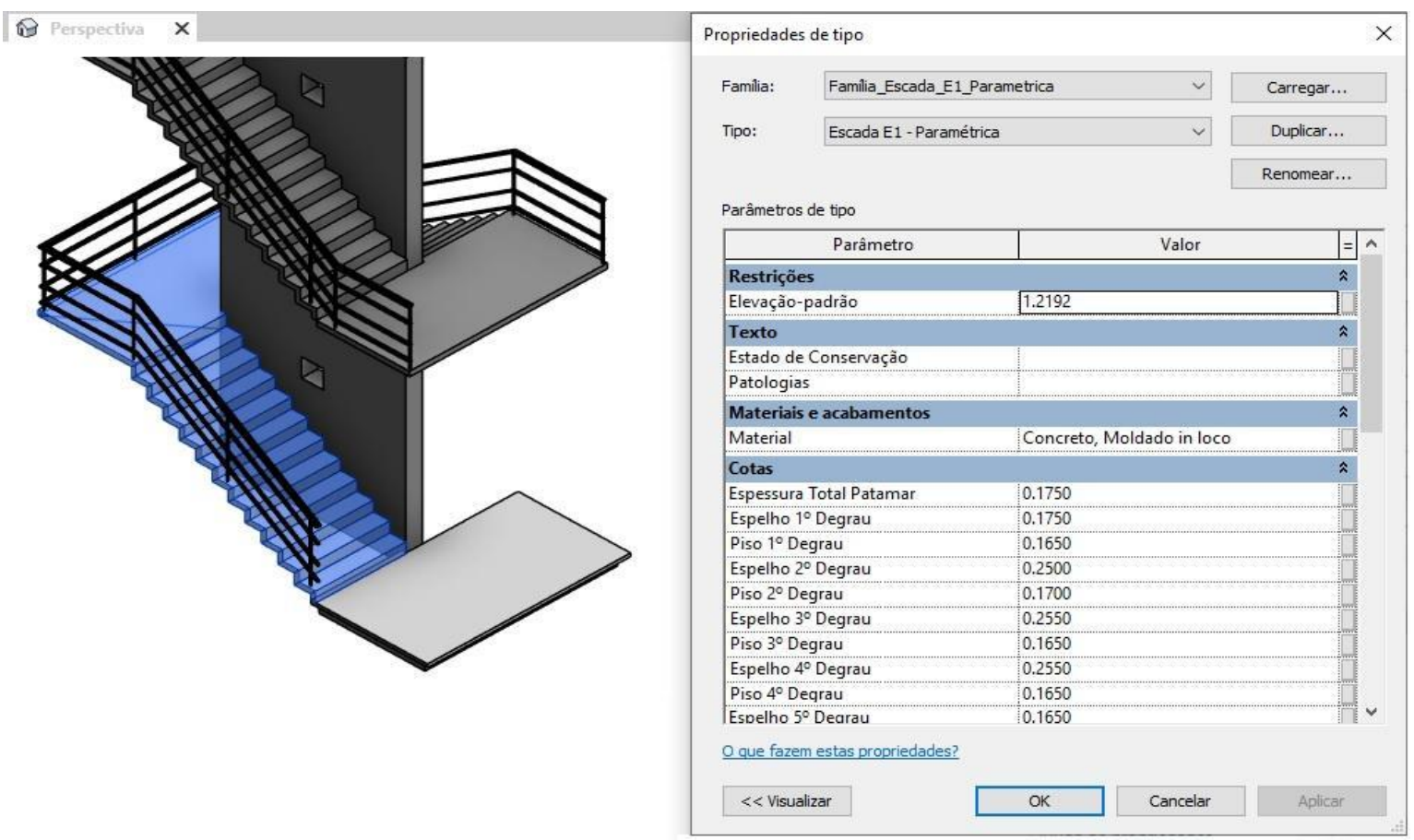

Fonte: Os autores.

Nessa forma de modelagem, o software identifica o modelo como uma massa genérica que pode incorporar quaisquer tipos de parâmetros dimensionais e textuais; por outro lado, perdem-se características paramétricas de representação da escada, o que exige a realização de ajustes manuais pelo projetista. $O$ elemento também perde a condição de hospedagem de guarda-corpo neste processo, sendo necessário que este seja modelado manualmente entre os pavimentos.

O aspecto relevante deste procedimento é que apesar de mais trabalhoso, produz um modelo mais preciso para documentar detalhes do elemento estudado, como a variação das dimensões entre degraus e itens complementares como uma grelha (Figura 10) situada no segundo degrau de cada lance da escada. Importante observar que não há possibilidade de inserção desta grelha nos procedimentos anteriores em virtude das características predefinidas dos degraus de uma família de sistema. 
Figura 10: Detalhe da grelha no edifício (a) e no modelo BIM (b).

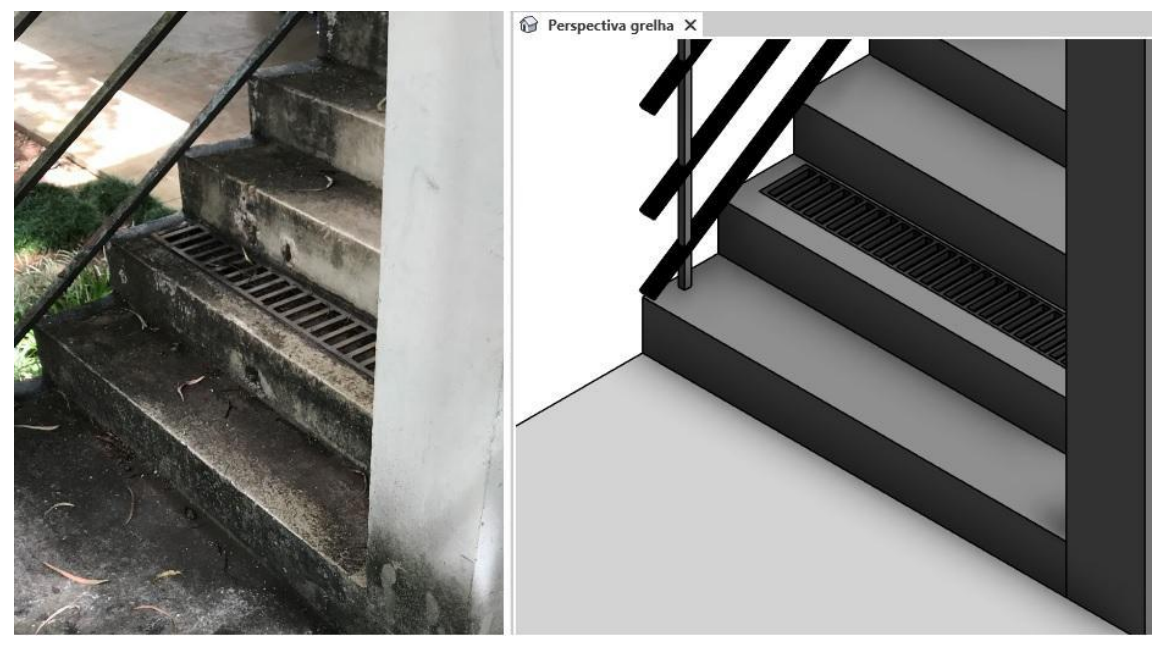

Fonte: Os autores.

Após a realização dos três procedimentos de modelagem, na Etapa 4 foi feita uma avaliação das famílias modeladas, que recorreu a um modelo BIM do edifício E1 - modelado em trabalhos anteriores do Grupo de Pesquisa Arquitec - para a verificação do comportamento dos componentes. O Quadro 2 sintetiza os resultados obtidos em cada procedimento descrito.

Quadro 2: Síntese dos resultados dos três processos de modelagem BIM.

\begin{tabular}{|c|c|c|}
\hline Tipo & Possibilidades & Limitações \\
\hline $\begin{array}{l}\text { Família de } \\
\text { Sistema }\end{array}$ & $\begin{array}{l}\text { Preserva as características automatizadas (como } \\
\text { cálculos dos degraus e ajustes normativos de } \\
\text { acessibilidade); o ajuste automático da escada nos } \\
\text { pavimentos é facilitado, mesmo havendo diferença } \\
\text { na altura entre níveis. A representação em planta } \\
\text { baixa é automatizada. É possível a hospedagem do } \\
\text { guarda-corpo automatizado na escada. }\end{array}$ & $\begin{array}{l}\text { Não é possível editar a forma do patamar, } \\
\text { somente os parâmetros de altura, largura e } \\
\text { espessura. Desse modo, não há como } \\
\text { representar formas geométricas } \\
\text { diferenciadas, como o formato piramidal do } \\
\text { patamar que a escada estudada apresenta. }\end{array}$ \\
\hline $\begin{array}{c}\text { Modelagem } \\
\text { Composta }\end{array}$ & $\begin{array}{l}\text { Foi possível executar a geometria piramidal } \\
\text { característica do patamar e adicionar informações } \\
\text { textuais nos atributos (como estado de conservação } \\
\text { e patologias aferidas em visitas). } \\
\text { Nos degraus mantém-se a hospedagem } \\
\text { automatizada do guarda-corpo e elementos de } \\
\text { representação do desenho na planta baixa. }\end{array}$ & $\begin{array}{l}\text { Não é possível adicionar informações } \\
\text { textuais nos atributos dos lances da escada } \\
\text { (por se tratar de uma família de sistema que } \\
\text { não permite a adição de campos de } \\
\text { informações). A representação do desenho } \\
\text { em planta baixa não é correta. Existe a } \\
\text { inconveniência de lidar com dois } \\
\text { componentes isolados no projeto para } \\
\text { compor a escada, enquanto a lógica do } \\
\text { sistema remete a um único elemento. }\end{array}$ \\
\hline $\begin{array}{c}\text { Família no } \\
\text { Local }\end{array}$ & $\begin{array}{l}\text { É o mais flexível disponível no software, permitindo } \\
\text { geometrias diversificadas, elementos } \\
\text { complementares (como a grelha) e a inserção de } \\
\text { diversos parâmetros (como espessura de degraus, } \\
\text { altura, largura, patamar e restrições associadas ao } \\
\text { dimensionamento dos elementos). Possibilita a } \\
\text { adição de campos para anotação de atributos } \\
\text { textuais (patologias, estado de conservação, etc). }\end{array}$ & $\begin{array}{l}\text { O software identifica o elemento como um } \\
\text { modelo genérico, não carregando parâmetros } \\
\text { automatizados disponíveis nas famílias de } \\
\text { sistema (como a hospedagem de guarda } \\
\text { corpo), exigindo modelagem manual. A } \\
\text { representação gráfica na planta baixa } \\
\text { também não é automatizada, demandando } \\
\text { inserção manual de anotações. }\end{array}$ \\
\hline
\end{tabular}

Fonte: Os autores.

\section{DISCUSSÃO DOS RESULTADOS}

Cada um dos três processos de modelagem trouxe contribuições para discussão sobre o desenvolvimento de famílias com aplicações em HBIM. A escada modelada seguindo o primeiro processo, por família de sistema, 
é o que melhor atende ao conceito de parametrização desejado aos modelos BIM, principalmente por manter relações com outros elementos do projeto e propriedades de representação arquitetônica mais adequada. No entanto, este processo não suporta a criação de formas geométricas distintas do padrão das famílias presentes na biblioteca do software, como no caso do patamar, algo muito comum quando estudamos edifícios históricos. Evidenciou-se maior conformidade da família modelada pelo segundo processo, a Família Composta, as características reais do edifício. Principalmente pelas possibilidades de ajustes dos patamares na forma como foi construído, inserção automática de espelhos e degraus, nivelamento com os pavimentos e hospedagem automática do guarda-corpo. A possibilidade de adição de atributos e parâmetros em certos elementos da modelagem define esse processo como uma parametrização parcial, fato relevante dependendo da finalidade do modelo. Porém, a representação gráfica nas vistas em planta baixa nesse processo é prejudicada, necessitando adequações manuais relevantes.

A escada produzida por meio do terceiro processo, por família no local, representa uma massa fixa, sem interação com outros componentes do modelo virtual, deixando de atender ao conceito de parametrização, que é o principal diferencial do BIM, conforme coloca Eastman et al. (2014). O software não possui a capacidade de identificar, nesse tipo de modelagem, o elemento como uma escada, deixando de atribuir parâmetros importantes de associação e representação dos elementos. No entanto, representa o modelo com mais flexibilidade formal na concepção, pois possibilita a realização de geometrias complexas, característica comumente encontrada nos projetos de edifícios históricos. Por outro lado, neste caso, o Revit passa a atuar apenas como software de modelagem simples, o que não justifica seu uso e a aplicação do conceito BIM nos elementos desenvolvidos.

Nos três processos, as famílias criadas podem ser exportadas para o formato IFC (Industry Foundation Classes), que é o padrão internacional de suporte à interoperabilidade para a indústria da construção. O IFC é um formato de exportação dos modelos para uso em múltiplas plataformas de softwares BIM, auxiliando processos de colaboração entre profissionais e disciplinas (KIRBY; KRYGIEL; KIM, 2018). Esta propriedade é importante no processo de modelagem de famílias HBIM para garantir que diferentes profissionais que venham a atuar nos projetos de conservação e manutenção do edifício possam utilizar corretamente as informações produzidas.

A modelagem destas famílias permitiu registrar com maior precisão, não somente as características geométricas do elemento do edifício, como informações semânticas das propriedades do estado atual do BEM. Este estudo exploratório corrobora as recomendações de Simeone et al. (2014) e Inzerillo et al. (2016), pois fornece uma base para uma eventual integração de sistemas ontológicos de informações alinhados com bancos de dados sobre o modelo HBIM.

Diante das características modernistas do edifício, pode-se inferir que não há necessidade de uso de softwares avançados e equipamentos com tecnologia de escaneamento a laser, conforme estudos correlatos apresentados (LÓPEZ et al., 2018; BRUSAPORCI; MAIEZZA; TATA, 2018), já que foi possível produzir resultados satisfatórios utilizando o software BIM e ferramentas de apoio mais acessíveis. Por outro lado, em situações de modelagem de edifícios com detalhes formais mais complexos, como no exemplo de barrocos e neoclássicos, seriam necessárias ferramentas de apoio a modelagem mais sofisticadas, em virtude das dificuldades evidenciadas por Banfi (2017) e Palomar et al. (2020). Conforme se pode verificar (Figura 11), os resultados obtidos por meio dos processos de modelagem descritos anteriormente demonstram a semelhança entre o modelo real (Figura 11-a) e o modelo virtual (Figura 11-b); abaixo dela tem-se a aplicação da família da escada no conjunto da obra (Figura 11-c).

Como resultado, tem-se ainda a constatação - durante medições no local - que a escada não foi executada exatamente como o projeto original da década de 1950. Há uma diferença na espessura do patamar, sendo $6 \mathrm{~cm}$ na parte final da inclinação da pirâmide; no entanto, foi executado com $8 \mathrm{~cm}$. Além disso, na representação gráfica do projeto original não é possível compreender a forma piramidal na base inferior do patamar. Nota-se a inclinação na planta do corte e na elevação, porém a leitura não é clara, o que poderia induzir a um erro de execução se não houvesse acompanhamento dos projetistas. Essa leitura de projeto seria facilitada com uma planta do teto do patamar e, principalmente, com representações em três dimensões. Tais características nortearam a busca pelas soluções mais adequadas ao registro de edifícios históricos virtualmente.

Além disso, verificou-se que, ao longo dos seus mais de 60 anos, o Edifício E1 apresentou alguns pontos que precisam de maior atenção e demandam projetos de manutenção e conservação, sobretudo ligados a reparos em sua estrutura, nos painéis cortina e na própria escada, que constituem elementos externos de grande destaque da edificação. 
Figura 11: Comparativo: (a) Fotografia do E1; (b) Perspectiva do Modelo BIM; (c) Representação ortográfica do Modelo BIM.
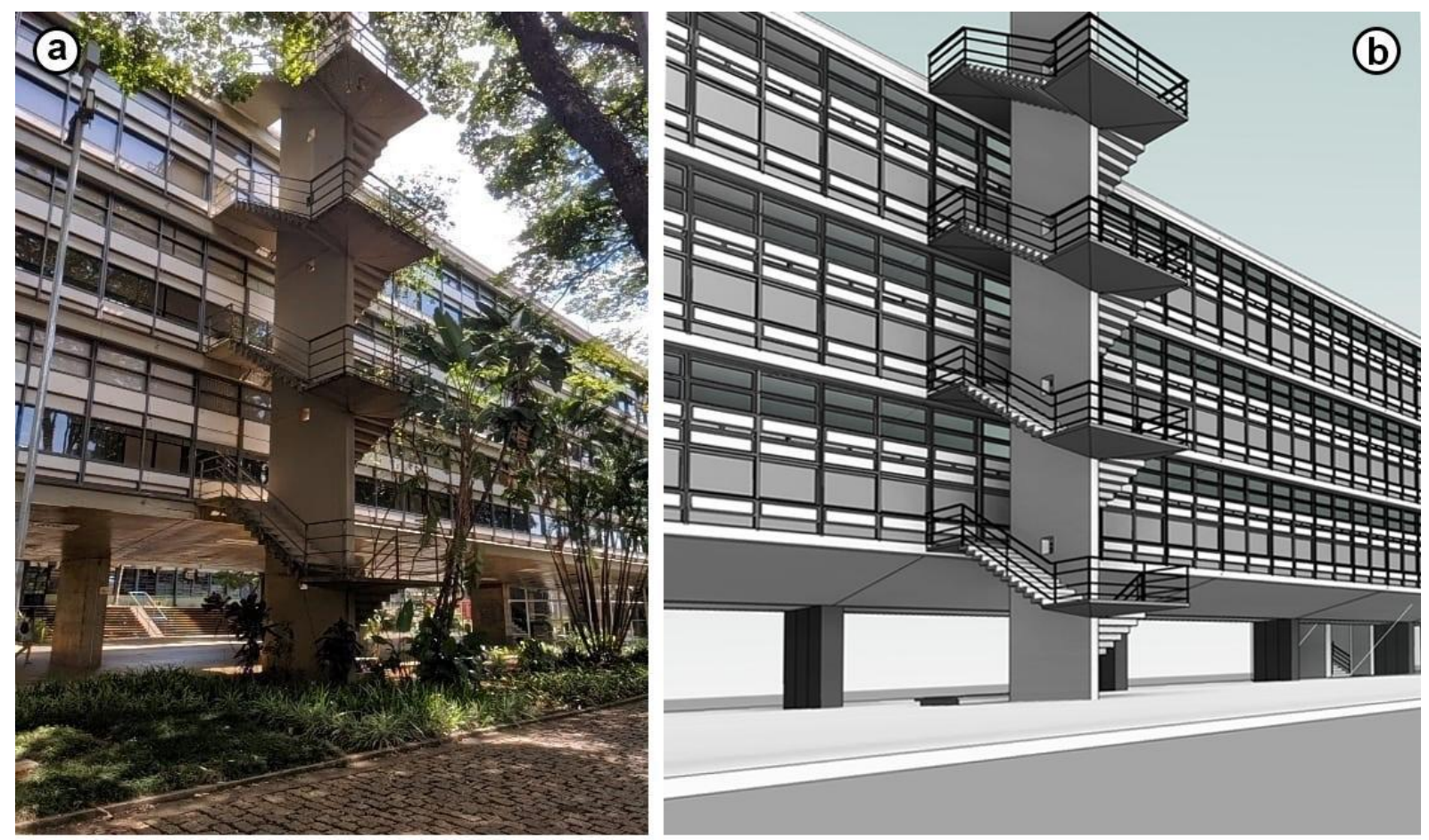

(C)

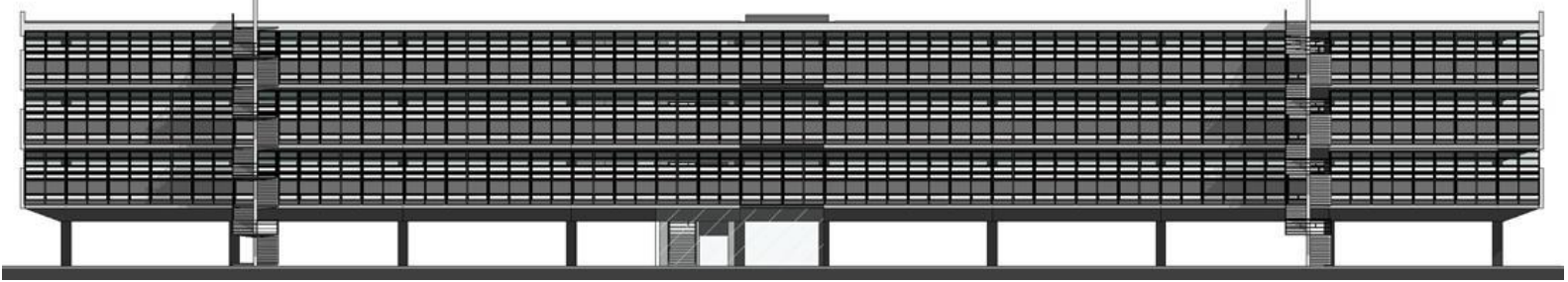

Fonte: Os autores.

\section{CONSIDERAÇÕES FINAIS}

Os resultados evidenciam as potencialidades e limitações que o emprego da tecnologia BIM pode trazer para a conservação e restauro do patrimônio arquitetônico de interesse histórico, especialmente no desafio de modelar famílias de componentes paramétricos a partir de atributos existentes. Pode-se afirmar que as famílias desenvolvidas neste estudo correspondem ao nível de detalhamento definido por Brumana et al. (2019) como LOG 100, caracterizado como uma primeira abordagem para discussão das edificações históricas, uma vez que não são utilizados equipamentos e processos de alta definição, como o escaneamento a laser, para o levantamento do edifício. Porém, devido às características modernistas do Edifício $\mathrm{E} 1$, questiona-se tal classificação pelo fato de referir-se a edifícios históricos com níveis de geometria extremamente complexos, como os clássicos, barrocos, góticos, entre outros. Esse fato demonstra que um levantamento realizado no local com equipamentos simples (como o do presente trabalho) pode produzir resultados precisos para a documentação do patrimônio, sobretudo em edifícios modernistas. No caso do edifício E1, cuja volumetria é caracterizada por planos e linhas retas, os processos produziram resultados satisfatórios, tendo em vista que o entorno do edifício é composto por massas vegetais que dificultariam levantamentos por scanners ou drones, como sugere os trabalhos de Brumana et al. (2019).

Da mesma forma, discute-se a especificação de LOD 500 e a ausência descritiva de seu nível no documento elaborado pelo AIA, dispensado por considerar este nível relacionado à verificação em campo de um edifício já construído (BIMFORUM, 2019). Conforme visto, a lógica da construção em BIM e sua classificação LOD se apoia em edifícios a serem construídos. No entanto, a definição "BIM para edifícios existentes", que não 
envolve apenas os edifícios históricos e culturais (VOLK; STENGEL; SCHULTMANN, 2014), demonstra que o processo de reengenharia digital em BIM para projetos de manutenção e conservação são cada vez mais necessários. As dificuldades enfrentadas na modelagem - seja na ordem de informações ou de geometria nem sempre permitem resultados com o grau de acuidade as-built e as-is, ou seja como no modelo real, o que solicita que o nível LOD de seus elementos seja estabelecido a fim de deixar claro o nível de desenvolvimento à equipe de projetos em situações de intervenções necessárias.

A pesquisa demonstra que diferentes graus de imprecisão estão presentes em uma edificação já construída, como no caso do E1. Algumas dessas imprecisões são provenientes de desvios do processo de construção - como as espessuras do patamar e dos degraus, em desacordo com o projeto original; e do próprio uso como patologias por fissuras, manchas por infiltrações, entre outras. A modelagem do estado atual, principalmente de uma edificação histórica, pede um registro que o BIM tem dificuldades de reproduzir, pois não possibilita a inserção de parâmetros como desvios do projeto original durante a construção, incorreções e patologias, conforme explicitou Palomar et al. (2020) sobre a dificuldade de modelagem das paredes onduladas, das patologias existentes, além dos elementos decorativos complexos.

Nesse sentido, a modelagem da família da escada do edifício E1 foi capaz de produzir informações relevantes sobre cada processo, contribuindo para uma ampliação da discussão sobre capacidade paramétrica, precisão geométrica e semântica dos elementos BIM, além das tecnologias e técnicas usadas. Sugere-se que cada processo de modelagem seja adotado em função da finalidade a que se destina o modelo HBIM. Nem sempre será importante ou necessário que um elemento histórico seja modelado para oferecer todos os recursos paramétricos como os de famílias BIM convencionais, uma vez que alguns elementos históricos são únicos e dificilmente serão reutilizados. No entanto, a modelagem deverá permitir uma fidelidade geométrica, associação de informações diversas, representação gráfica correta e o estabelecimento do nível de desenvolvimento, itens importantes para o registro e gestão da conservação e manutenção do patrimônio. Para tanto, os recursos dos softwares devem dar flexibilidade nessa reconstrução.

Cabe destacar que este estudo é exploratório sobre a aplicação dos conceitos BIM na modelagem de famílias para registro do patrimônio histórico construído, contribuindo com informações práticas. Buscou-se desenvolver competências para entender como as informações podem ser coletadas, de que forma podem ser modeladas em BIM, especificamente no Revit (versão 2019), e quais resultados podem ser obtidos. Constata-se que $03^{\circ}$ Processo de modelagem poderia ser utilizado para elementos com geometrias curvas e irregulares, uma vez que este permite uma maior flexibilidade formal, mesmo com os limites de representação gráfica apresentados. No entanto, outros softwares sob o conceito BIM devem ser testados em trabalhos futuros, a fim de averiguar o comportamento paramétrico dos elementos, o alcance da geometria desejada e a inclusão de informações, tanto para edifícios da arquitetura moderna, quanto da clássica, barroca ou outras de formas não euclidianas, com maior complexidade e desafios.

Além disso, nota-se na prática que a dificuldade no desenvolvimento de famílias pelo Revit leva os projetistas a fazerem uso de outros softwares de modelagem para em seguida exportarem para o programa. É preciso testar a conservação das propriedades de parametrização dos objetos exportados usando o padrão IFC entre os vários programas existentes.

Por fim, o material produzido apoia projetos de conservação, manutenção e restauro do Edifício E1, em face a sua importância histórica na arquitetura moderna brasileira, como um marco do início da construção do campus São Carlos da Universidade de São Paulo. Contribui para a maior precisão do registro do edifício em BIM, gerando subsídios para a criação de um projeto 'as is', que proporcionará maior compreensão das especificidades da obra edificada em seu estado atual, com atualização das dimensões executadas e as demandas durante seu uso. Também colabora, ainda que de forma exploratória, para um maior conhecimento sobre modelagem de famílias BIM, seus processos, ferramentas, possibilidades e limitações, especialmente de elementos históricos que são exclusivos e não presentes em bibliotecas públicas ou de interesse comercial de marcas de fabricantes atuantes no mercado.

O modelo HBIM da escada do Edifício E1 está disponível para download no endereço eletrônico do grupo de pesquisa Arquitec $^{8}$. Com isso, colabora-se com a composição e disseminação de uma biblioteca HBIM, com conteúdo de acesso público sobre patrimônio histórico que será alimentado ao longo do tempo com novas discussões dos processos e ferramentas existentes.

\section{AGRADECIMENTOS}

À Universidade Federal do Tocantins (UFT), pelo afastamento para qualificação nível doutorado concedido à primeira autora; à CAPES, pela bolsa de doutorado - Processo 88882.379077/2019-01; pela bolsa CAPES Print - Processo 88887.465541/2019-00; à USP, pela bolsa do Projeto Unificado de Bolsas (PUB) - Processo 
2453/2019; ao CNPq, pela bolsa PIBIC - Processo 1755/2019; pela bolsa produtividade - Processo 306998/2018-1; pelo auxílio à pesquisa, Chamada Universal - Processo 435740/2018-0.

Agradecemos também à Escola de Engenharia de São Carlos da USP, pelo acesso às instalações físicas do E1; à Divisão do Espaço Físico (DVEF) e a Divisão de Obras, Manutenção e Operação (DVMANOPER) da Prefeitura do Campus USP de São Carlos, em especial à arquiteta Sônia Lúcia Medeiros da Silva Costardi, pela disponibilização dos projetos originais do edifício e autorização de uso; ao engenheiro Júlio César Franco Jr., por gentilmente fornecer a fotografia do edifício E1 apresentada na Figura 1 (c).

\section{REFERÊNCIAS}

AMORIM, A. L. Methodological Aspects of Architectural Documentation. Geoinformatics FCE CTU, v. 6, p. 34-39, 2011. DOI: https://doi.org/10.14311/gi.6.5.

AUTODESK, 2019. Autodesk knowledge network. Sobre os diferentes tipos de família. Disponível em: https://bityli.com/QBD8H. Acesso em: 16 mar. 2020.

BANFI, F. BIM orientation: grades of generation and information for different type of analysis and management process. In: The International Archives of the Photogrammetry, Remote Sensing and Spatial Information Sciences, Ottawa, Canada. DOI: https://doi.org/10.5194/isprs-archives-XLII-2-W5-57-2017.

BARAZZETTI, L.; BANFI, F.; BRUMANA, R. Historic BIM in the Cloud. In: IONNIDES, M. et al. (eds.). Digital Heritage. Progress in Cultural Heritage: Documentation, Preservation and Protection. Nicósia: Springer, 2016. DOI: https://doi.org/10.1007/978-3-319-48496-9 9.

BRACHT, M. O que são componentes e famílias BIM? - 2018. Disponível em: https://bimnapratica.com/ blog/componentes-e-familias-bim. Acesso em: 28 out. 2019.

BIMForum, 2019. Level of Development (LOD) - Specification Part 1 \& Commentary for Building Information Models and Data. Versão: abril de 2019. Disponível em: https://bimforum.org/LOD/. Acesso em: 10 de abr. 2020.

BRASIL. Decreto no 9.983, de 22 de agosto de 2019. Dispõe sobre a Estratégia Nacional de Disseminação do Building Information Modelling e institui o Comitê Gestor da Estratégia do Building Information Modelling. Disponível em: http://www.planalto.gov.br/ccivil 03/ ato2019-2022/2019/decreto/D9983.htm. Acesso em: 16 mar. 2020.

BRASIL. Decreto no 10.306, de 2 de abril de 2020. Estabelece a utilização do Building Information Modelling na execução direta ou indireta de obras e serviços de engenharia realizada pelos órgãos e pelas entidades da administração pública federal, no âmbito da Estratégia Nacional de Disseminação do Building Information Modelling - Estratégia BIM BR. Disponível em: http://www.planalto.gov.br/ccivil 03/ ato2019-2022/2020/Decreto/D10306.htm. Acesso em: 28 mai. 2020.

BRUNO, S.; DE FINO, M.; FATIGUSO, F. Historic Building Information Modelling: performance assessment for diagnosisaided information modelling and management. Automation Construction, online, v. 86, p. 256-276, 2018. DOI: https://doi.org/10.1016/j.autcon.2017.11.009

BRíGITTE, G. T. N.; RUSCHEL, R. C. Modelo de informação da construção para o projeto baseado em desempenho: caracterização e processo. Ambiente Construído, Porto Alegre, v.16, n. 4, p.09-26, out./dez. 2016.

BRUMANA, R.; BANFI, F.; CANTINI et al. HBIM Level of Detail - Accuracy and Survey analysis for architectural preservation. In: The International Archives of the Photogrammetry, Remote Sensing and Spatial Information Sciences, Volume XLII-2/W11, 2019 / GEORES 2019 - 2nd International Conference of Geomatics and Restoration, 8-10 May 2019, Milan, Italy, Italy, 2019. DOI: https://doi.org/10.5194/isprs-archives-XLII-2-W11-293-2019.

BRUSAPORCI, S.; MAIEZZA, P.; TATA, A. A framework for architectural heritage HBIM Semantization and development. In: International archives of the photogrammetry, remote sensing and spatial information sciences, XLII-2, p. 179-184, 2018. DOI: https://doi.org/10.5194/isprs-archives-XLII-2-179-2018.

CIRIBINI, A. L. C.; VENTURA, S. M.; PANERONI, M. BIM methodology as an integrated approach to heritage conservation management. WIT Transactions on The Built Environment (online), v. 149, 2015. DOI: https://doi.org/10.2495/BIM150231.

COUNSELL, J.; ARAYICI, Y. Chapter 1 - Introduction. In: ARAYICI, Y.; COUNSELL, J.; MAHDJOUBI, L.; NAGV, G.; HAWAS, S.; DEWIDAR, K. (org.) Heritage Building Information Modelling. London and New York: Routledge - Taylor \& Francis Group, p. 1-5, 2017. DOI: https://doi.org/10.4324/9781315628011.

CUPERSCHMID, A. R. M.; FABRICIO, M. M.; FRANCO JR., J. C. HBIM Development of a Brazilian modern architecture Icon: Glass House by Lina Bo Bardi. Heritage, p. 1927-1940, 2019. DOI: https://doi.org/10.3390/heritage2030117.

DEZEN-KEMPTER, E.; SOIBELMAN, L.; CHEN, M.; MÜLLER, A.V. Escaneamento 3D a laser, fotogrametria e modelagem da informação da construção para gestão e operação de edificações históricas. Gestão e Tecnologia de Projetos, São Paulo, v. 10, n. 2, p. 113-124, jul./dez. 2015. DOI: http://dx.doi.org/10.11606/gtp.v10i2.102710.

DORE, C.; MURPHY, M. Current state of the art historic building information modelling. In: The International Archives of the Photogrammetry, Remote Sensing and Spatial Information Sciences, Ottawa, 2017. DOI: https://doi.org/10.5194/isprsarchives-XLII-2-W5-185-2017. 
EASTMAN, Chuck et al. Manual de BIM: um guia de modelagem da informação da construção para arquitetos, engenheiros, gerentes, construtores e incorporadores. Porto Alegre: Bookman, 2014.

FAI, S., RAFEIRO, J. Establishing an appropriate level of detail (LoD) for a building information model (BIM) - West Block, Parliament Hill, Ottawa, Canada. In: ISPRS Annals of the Photogrammetry, Remote Sensing and Spatial Information Sciences, Riva del Garda, p. 123-130, 2014. DOI: https://doi.org/10.5194/isprsannals-II-5-123-2014.

FIALHO, B. C.; COSTA, H. A.; FABRICIO, M. M. Coordenação Modular e BIM: contribuições a partir do estudo do Edifício E1 da Escola de Engenharia de São Carlos. Arq.Urb, São Paulo, n. 22, p.43-65, mai./ago. 2018.

FRANCO JR, J. C. Perspectiva aérea Edifício E-1. 2017. 1 fotografia, color.

GROETELAARS, N. J. Criação de Modelos BIM a partir de "Nuvens de Pontos": Estudo de Métodos e Técnicas Para Documentação Arquitetônica. 2015. Tese (Doutorado) Programa d Pós-graduação em Arquitetura e Urbanismo) Faculdade de Arquitetura, Universidade Federal da Bahia, Salvador, 2015.

HISTORIC ENGLAND, 2017. BIM for Heritage: Developing a Historic Building Information Model. Historic England: Swindon, UK, 2017. Disponível em: https://historicengland.org.uk/advice/technical-advice/recording-heritage/. Acesso em: 03 de mai. 2020

INZERILLO, L.; LO TURCO, M.; PARRINELLO, S.; SANTAGATI, C.; VALENTI, G. M. BIM and architectural heritage: towards an operational methodology for the knowledge and the management of Cultural Heritage. Disegnarecon, vol. 9, n. 16, p. 16.1-16.9, 2016.

KIRBY, L; KRYGIEL, E.; KIM, M. Mastering Autodesk Revit 2018. Indianapolis: John Wiley \& Sons, 2017.

LÓPEZ, F. J.; LERONES, P. M.; LLAMAS, J.; BERMEJO, J. G. G.; ZALAMA, E. A Review of Heritage Building Information Modeling (H-BIM). Multimodal Technologies and Interact, v. 21 (2), 2018. DOI: https://doi.org/10.3390/mti2020021.

LU, D.; PAN, Y. Digital Preservation for Heritages. Technologies and Applications. London: Springer, 2010.

MURPHY, M.; MCGOVERN, E.; PAVIA, S. Parametric Vector Modelling of Laser and Image Surveys of 17th Century Classical Architecture in Dublin. In: The 8 th International Symposium on Virtual Reality, Archaeology and Cultural. Brighton, UK, 2007. Disponível em: http://www.riegl.co.at/uploads/tx pxpriegldownloads/project 2006 .pdf. Acesso em: 10 de mar. 2020.

MURPHY, M; MCGOVERN, E; PAVIA, S. Historic building information modelling (HBIM). Structural Survey, v. 27, n. 4, p. 311-327, 2009. DOI: http://dx.doi.org/10.1108/02630800910985108.

MURPHY, M.; MCGOVERN, E.; PAVIA, S. Historic Building Information Modelling - Adding intelligence to laser and image based surveys of European classical architecture. ISPRS Journal of Photogrammetry and Remote Sensing, v. 76, p. 89102, 2013. DOI: https://doi.org/10.1016/j.isprsiprs.2012.11.006.

NOBRE, A. L. Módulo só: o edifício E1, em São Carlos, de Ernest Mange e Hélio Duarte. Risco: Revista de Pesquisa em Arquitetura e Urbanismo (online), v. 5, p. 22-32, 2007. DOI: https://doi.org/10.11606/issn.1984-4506.v0i5p22-32.

NOSELLA, P.; BUFFA, E. Escola de Engenharia de São Carlos: os primeiros tempos: 1948-1971. São Carlos: EDUFSCAR, 2000

PALOMAR, I. J.; TZORTZOPOULOS, P.; VALLDECABRES, J. L. G; PELLICER, E. Protocol to Manage Heritage-Building Interventions Using Heritage Building Information Modelling (HBIM). Sustainability, v. 10, n. 908, p. 2-19, 2018. DOI: http://dx.doi.org/10.3390/su10040908.

PALOMAR, I. J.; TZORTZOPOULOS, P.; VALLDECABRES, J. G.; PELLICER, E. An online platform to unify and synchronise heritage architecture information. Automation Construction, v. 110, p. 1-17, 2020. DOI: https://doi.org/10.1016/j.autcon.2019.103008.

PREFEITURA DO CAMPUS USP - SÃO CARLOS. Manutenção Geral - Divisão do Espaço Físico (DVEF). São Carlos: Universidade de São Paulo, Departamento de Obras, Infraestrutura, 2017.

SIMEONE, D.; CURSI, S.; TOLDO, I.; CARRARA, G. BIM and knowledge management for building heritage. In: Annual Conference of the Association for Computer Aided Design in Architecture (ACADIA), n. 34, Los Angeles, 2014. Proceedings... Los Angeles, p. 681-690, 2014.

SUCCAR, B.; KASSEM, M. Macro-BIM adoption: Conceptual structures. Automation in Construction, v. 57, p. 64-79, 2015. DOI: https://doi.org/10.1016/j.autcon.2015.04.018.

SUCCAR, B. Building information modelling framework: A research and delivery foundation for industry stakeholders. Automation in Construction, v.18, p 357-375, 2009. DOI: https://doi.org/10.1016/j.autcon.2008.10.003.

UNESCO. Convenção para a Proteção do Patrimônio Mundial, Cultural e Natural. Conferência Geral da Organização das Nações Unidas para a Educação, a Ciência e a Cultura. Paris, 1972. Disponível em: https://unesdoc.unesco.org/ark:/48223/pf0000133369 por. Acesso em: 12 de abr. 2020. 
VAN BERLO, L. A. H. M.; BOMHOF, F. Creating the Dutch National BIM Levels of Development (extended). In: International Conference on Computing in Civil and Building Engineering, 2014, Orlando, USA. Proceedings.... Orlando: American Society of Civil Engineers (ASCE), p. 129-136, 2014. DOI: https://doi.org/10.1061/9780784413616.017.

VOLK, R.; STENGEL, J.; SCHULTMANN, F. Building Information Modeling (BIM) for existing buildings - Literature review and future needs. Automation in Construction, v. 38, p. 109-127, $2014 . \quad$ DOI: http://dx.doi.org/10.1016/j.autcon.2013.10.023.

\section{NOTAS}

$1 \mathrm{O}$ termo NURBS significa Non-Uniform Rational B-Splines. Trata-se de uma ferramenta para modelar superfícies irregulares com mais facilidade. Conceito extraído do suporte da Autodesk. Disponível em: https://knowledge.autodesk.com/pt-br/support/3ds-max/learnexplore/caas/CloudHelp/cloudhelp/2019/PTB/3DSMax-Modeling/files/GUID-C99618D4-8AB8-4476-A313-4D4519B0DDCF-htm.html. Acesso em 28 de maio de 2020.

2 Disponível em: https://bimforum.agc.org/lod/, acesso em 28 de maio de 2020.

${ }^{3}$ Disponível em: https://produtostecnicos.fde.sp.gov.br/Login.aspx, acesso em 16 de março de 2020.

${ }^{4}$ Disponível em: http://contier.com.br/downloads, acesso em 16 de março de 2020.

${ }^{5}$ Aplicativo Trnio® - Disponível em: https://www.trnio.com/, acesso em 28 de maio de 2020.

${ }^{6}$ As categorias de template disponíveis no software incluem: anotações, estruturas, instalações elétricas, hidráulicas, esquadrias e modelos genéricos baseados em faces, linhas, paredes, pisos, forros, telhados, entre outros.

7 Disponível em: https://arquitec.iau.usp.br/projetos/edif\%C3\%ADcio-e1, acesso em 28 de maio de 2020.

${ }^{8}$ Endereço do grupo Arquitec | IAU USP: https://arquitec.iau.usp.br/produ\%C3\%A7\%C3\%A3o/biblioteca-bim.

NOTA DO EDITOR $\left({ }^{\star}\right)$ : O conteúdo do artigo e as imagens nele publicadas são de responsabilidade do(s) autor(es). 